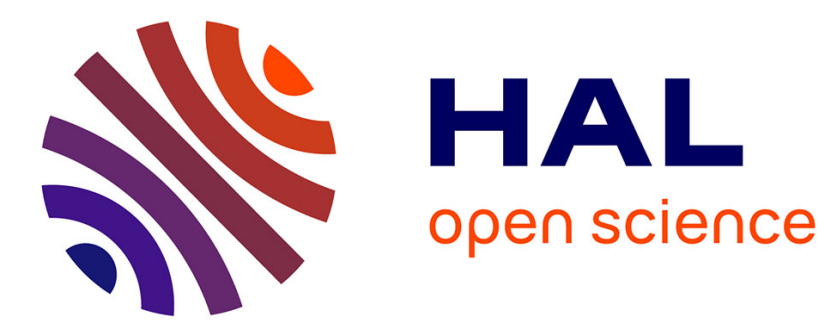

\title{
Le cimetière des anciens Bretons de Saint-Urnel ou Saint-Saturnin en Plomeur (Finistère)
}

Pierre-Roland Giot, Jean-Laurent Monnier

\section{To cite this version:}

Pierre-Roland Giot, Jean-Laurent Monnier. Le cimetière des anciens Bretons de Saint-Urnel ou SaintSaturnin en Plomeur (Finistère). Gallia - Fouilles et monuments archéologiques en France métropolitaine, 1977, 35 (1), pp.141-171. 10.3406/galia.1977.1559 . hal-01939338

\section{HAL Id: hal-01939338 \\ https://hal.science/hal-01939338}

Submitted on 14 Jun 2020

HAL is a multi-disciplinary open access archive for the deposit and dissemination of scientific research documents, whether they are published or not. The documents may come from teaching and research institutions in France or abroad, or from public or private research centers.
L'archive ouverte pluridisciplinaire HAL, est destinée au dépôt et à la diffusion de documents scientifiques de niveau recherche, publiés ou non, émanant des établissements d'enseignement et de recherche français ou étrangers, des laboratoires publics ou privés.

\section{(ㅇ)(1) $\$$}

Distributed under a Creative Commons Attribution - NonCommercial - NoDerivatives 44.0 


\title{
LE CIMETIÈRE DES ANCIENS BRETONS DE SAINT-URNEL OU SAINT-SATURNIN EN PLOMEUR (Finistère)
}

\author{
par Pierre-Roland GIOT et Jean-Laurent MONNIER
}

Le cimetière de Saint-Saturnin (toponyme du cadastre, des cartes, de la liste électorale, du répertoire des lieux-dits de l'I.X.S.E.E.) ou de Saint-Lrnel (forme des publications archéolog̣iques depuis 1881, suivant la prononciation locale) est situé sur une butte à substratum granitique dominant les "palues " sableuses de la Baie d'Audierne, immédiatement au sud des édifices de l'ancienne ferme de Saint-Saturnin, dite aussi Saint-Crnel-Bras, à cheval sur les parcelles 18 et 19 de la section $\mathrm{Al}$ du callastre révisé (1952). Le site fut découvert au siècle dernier, vers 1880 , un grand nombre de squelettes ayant été mis au jour lors d'une exploitation en carrière du granite sous-jacent. P. Du Châtellier ${ }^{1}$, l'érudit archéologue de ce secteur, au vu de la céramique grossière associée, des silex, des percuteurs et des pierres à concasser le grain découverts à côté des squelettes, les avait considérés comme "gaulois»; il en releva quelques-uns lui-mème et ne conserva que trois crânes.

Le site fut fouillé de 1920 à 1924 par les premiers archéologues du Groupe finistérien d'études préhistoriques ${ }^{2}$, fondateurs du Nusée préhistorique finistérien à Saint-GuénoléPenmarc'h, et quelques squelettes servirent de base à la première exposition ; à vrai dire la nécropole de Saint-lirnel fut l'un des trois sites ou chantiers ayant déterminé l'existence de l'association et celle du Vusée. Toute une stratigraphie dunaire fut mise en évidence :

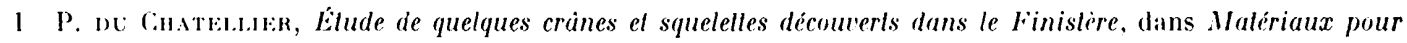

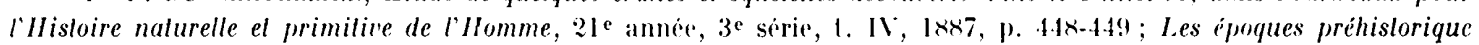

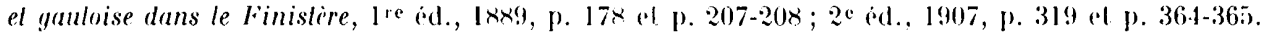

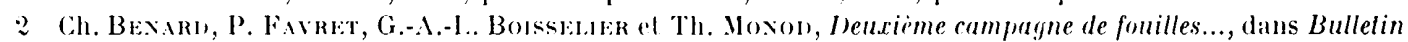

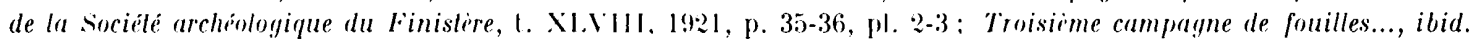

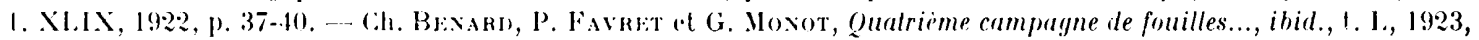
p. 83-93, fig. 1-9. - 1'. Favret of (h. Briskn, Les deux nécropoles de saint-l'rnel el de Roz-an-Tre-Men en Plomeur,

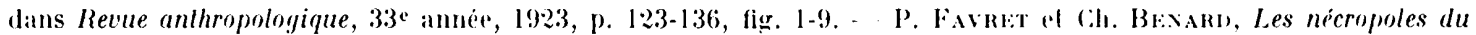
Finislere, dans Reve archeologique, 1. XIX, 1924, p. 179-194 seul article lenant compte de la derniere campagne,

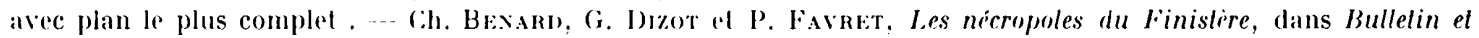
Mémoires de l'Institut finistérien déludes préhistoriques, nos 2-3-4, 192-4-1925-1926 1927, p. 1-20 (même article. -

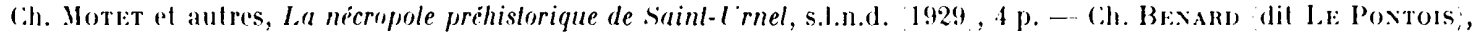
I.e Finistere Próhistorique, 1929, p. 220-230 ol 290-291. 
les niveaux ou étages inférieurs furent considérés d'abord comme pouvant peut-être se trouver très anciens, pour des raisons d'archaïsmes anthropologiques, puis ils furent, rajeunis et l'on admit que les premières tombes datables remontaient à l'Âge du Bronze final. Les débris de poterie découverts parmi les sables emballant ces tombes furent à juste titre attribués aux débuts de l'Âge du Fer pour la plupart d'entre eux. Les niveaux supéricurs furent considérés comme de l'Âge du Fer pour continuer jusqu'au gallo-romain au vu de meules rotatives à vrai dire non caractéristiques car discoüdes. En définitive on étalait la formation de la nécropole sur les quelques siècles précédant l'ère chrétienne, le tout avec d'assez bons motifs. Vers 1929, il y eut bien quelques réticences exprimées dans des articles de journaux locaux; elles avaient été inspirées par S. J. Péquart qui avait fait des comparaisons entre les entourages des tombes supérieures et ceux du cimetière médiéval de saintClément à Quiberon où il avait jadis fouillé ; elles avaient aussi été inspirées par le fait que (i. Monot, érudit local, avait retrouvé la tradition de l'envahissement par les dunes en l'année 1111 (dite "des quatre bâtons »). Valarlroitement formulées ${ }^{3}$ ces réserves furent sans suites.

Reprenant le Husée préhistorique finistérien en 1945), il était naturel, etant donné les recherches sur l'anthropobiologie de l'Armorique auxquelles se consacrait alors l'ainé d'entre nous, qu'il attache une grande importance à ce gisement, et il en reprit la fonille de 1946 à 1950, assisté par J. Cogné4. Line petite extension romplémentaire fut fouillée en 1951 par F. Barillet. Ces recherches avaient confirmé que le sol ancien sous-jacent à la nécropole renfermait des résidus d'industries variées allant du Véolithique jusqu'au Bronzr final. On n'avait pas découvert non plus d'arguments permettant d'infirmer les datations proposées antérieurement, lesquelles pouvaient trouver valablement appui sur les sépultures à inhumation dérouvertes en association aver maints sites bien dates de l'Àge du Far dans la région, interstratifiés dans le même système de dunes. A rotte époque des investigations, la datation radiocarbone n'était pas encore entrée en application, ef clle fut longtemps incertaine pour les déterminations d'âge des ossements.

Mais un doute pouvait subsister, que nous arons été amenés à cultiver. L'absence de tout mobilier funéraire ne permettait aucune autre approche pour apprécier l'âge de ces sépultures. On a continué à citer provisoirement Saint-Lrnel comme un cimetière de l'îger du Fer dans des publications générales, car il fallait bien le situer quelque part. le gisement était trop connu pour être passé sous silence. Aussi lorsque ces toutes dernièress années des méthodes valables et fiables de datation radiocarbone sur ossements ont été enfin au point (sur le collagène résiduel des os, et donc en éliminant tout le carbonate de chaux), nous nous sommes empressés d'en obtenir, grâce à la bonne coopération de ll me (i. Lélibrias ${ }^{5}$. Elles ont montré qu'il s'agissait d'un cimetière breton du Haut Moyen Âge, donc un rajeunissement moyen de l'ordre de mille ans. Rien n'est plus difficile que de modifier une datation rommunément admise; nous en avions enfin less moyens.

3 V. B. dans Onest-Echair édition dr Quimper, $1 \times$ janvier 1929,8 février 1929,14 févier 1929.

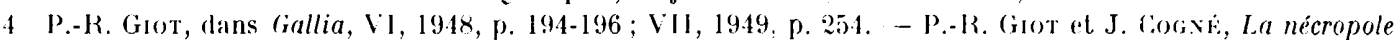
de Saint-Urnel en Plomeur (Finislère), fouilles de 1946-19.50, dans Gallia, IX, 1951, p. 1-19. 12 fig.

5 P.-K. Giot, dans Innales de Brelagne, 1.XXX, 1973, p. 129-136 el p. 1.11. 

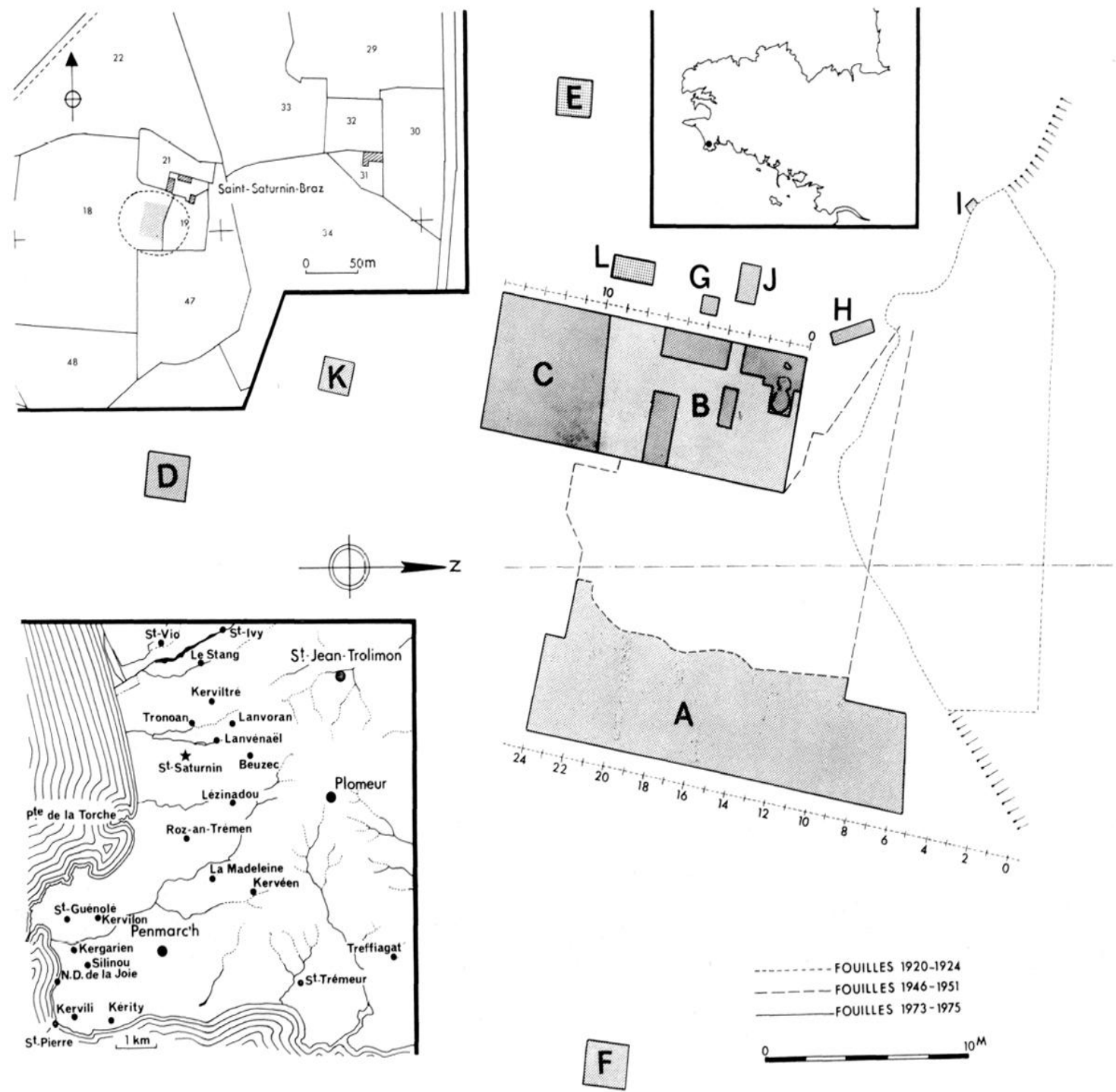

1 Plans et cartons de situation des fouilles de Saint-Saturnin. Situation en Bretagne. Carton de situation dans le Cap-Caval, avec indication des lieux-dits significatifs au point do vue religieux ol des lieux-dits mentionnés dans les carlulaires ot identifiés. Plan cadastral, en lirete siluation d'ensemble du sile, en tramé zone principale des fouilles. Plan principal, ave indication des emplacements des fonilles anterieures, situation des chantiers et sondages des fouille's nouvelles.

lërifier et prolonger ces indicitions sur le terrain était nécessaire pour en tirer leurs pleines conclusions, d'autant plus qu'elles ourraient des perspectives attirantes sur les périodes les plus assombries, à l'aube de l'histoire de la Bretagne. Aussi après une longue interruption, nous avons été amenés, de 1973 à 1975), à travailler à nouveau sur le chantier de Saint-saturnin. aver des moyens de recherches renouvelés. Nous remercions les proprié-

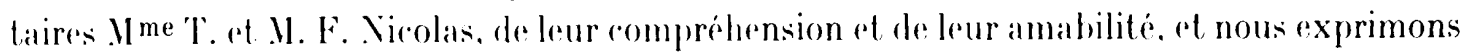
notre gratitude au serviere des Fouilles et Antiquités, ainsi quau Conseil Général du Finistère, romme à l'l'niversité de Rennes et au C.X.R.s. pour nous avoir alloué les moyens matériels nécessaires à cette recherche. 
Les fouilles proprement dites ont eu lieu chaque année lors de deux phases complémentaires. Lne premiere, en saison, avec un groupe de stagiaires bénevoles, suivie épisodiquement jusqu'à l'automne de travaux complémentaires en petite équipe. Les signataires ont été souvent aidés de leurs collaborateurs de laboratoire J.-R. Bourhis et Y. Onnée; parni les concours locaux ils ont souvent eu ceux de J. Peuziat, docteur en chirurgie dentaire, et de P. Berrou et B. Poignant, professeurs agrégés ${ }^{6}$.

L'ancienne carrière s'était entaillée dans la moitié septentrionale de la butte de SaintSaturnin. Las fouilles de 1920 à 1924 avaient été conduites le long du front de taille abandonné, à peu près au maximum d'épaisseur des sables et terres accumulés au-dessus du socle rocheux. Jepuis lors le front s'était éboulé et dégradé. On ne peut estimer que d'une manière approximative la situation des premières fouilles par rapport à celles de 1946 à 1951. Les travaux de 1950-1951 atteignaient la retombée méridionale de la butte, encore sous culture. Après leur comblement les terrains sont retombés en friche à la suite de l'abandon de la ferme. Le plan d'implantation des campagnes 1973-1974-1975) (fig. 1) s'efforee done de situer aussi les recherches antérieures.

On ignore la surface exacte détruite par la carrière, du côté nord ; ce cimetière aura été exploré entre 1920 et 1975 sur près de 500 $\mathrm{m}^{2}$. Ies sondages (E, K, F, positifs ; D, négatif) donnent une rélimitation minimale de la zone des inhumations; il doit rester au moins $1000 \mathrm{~m}^{2}$, soit une confortable réserve archéologique. A l'issue des fouilles les exravations ont éte completement remblayées de sorte qu'il ne reste rien de visible. I'ailleurs la ferme est devenue une résidence secondaire.

Le cimetiere étant formé d'une accumulation de sépultures orientées est-ouest, pour dégager le maximum de tombes entières il est indiqué de procéder par le décapage de rectangles à plus grande dimension elle-même est-ouest, et c'est la technique qui arait été suivie lors des fouilles 1946-1900. Mais nous souhaitions par contre pouvoir étudier de manière plus détaillée les relations de position des tombes les unes par rapport aux autres. Aussi, en 1973-1974, au risque de recouper un plus grand nombre d'inhumations par le milieu, on prit l'avantage d'une grande section transversale en implantant un rectangle de décapage (A) à plus grande dimension nord-sud. Son bord oriental s'est appuyé sur le petit talus séparatif des parcelles 18 et 19, zone perturbée. Pour avoir une belle section continue, on a donc placé le bord occidental de cette grande fouille à une petite distance du bord des fouilles antérieures, la zone de raccord ayant été résorbée à la fin des opérations.

Ln deuxième chantier (I3) s'est attaqué à un massif de blocailles et de ruines autour duquel les anciennes fouilles avaient tourné sans qu'on n'en comprenne la nature, près de la zone la plus élevée du tertre. Par tranches successives du nord au sud, les lrois campagness en ont exploré la moitié orientale encastrée sur le bord occidental du cimetière, laissant d'ailleurs en place les structures les plus intéressantes. Le présent article n'abordera pas la fouille et l'interprétation de ce secteur. On doit simplement dire que ces ruines se sont montrées superposées à des inhumations des phases anciennes du cimetière.

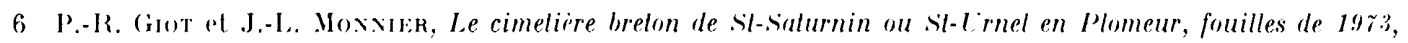

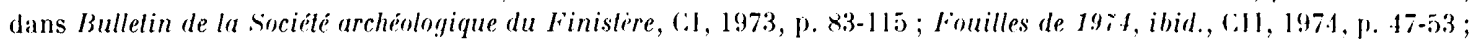

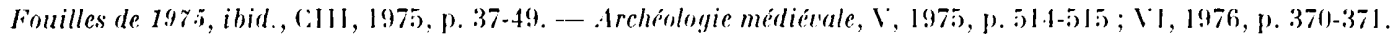


Ln troisième chantier (C), ouvert seulement en 1975, a été implanté dans le cimetière immédiatement au sud et à toucher le chantier $B$, de manière à mieux comprendre les relations du cimetière et des édifices, ceux-ci étant en partie superposés aux phases les plus anciennes du cimetière. La limite est des chantiers $B$ et Ci venait buter sur les zones foullées entre 1947 et 1951, les raccords ayant été dégradés entre temps par des éboulements. Cependant les quatre còtés du rectangle Ciont donné de belles sections, seule la partie nord de sa limite orientale se trouvant près du remblayage des fouilles anciennes, et donc instable. Cne série de sondages complémentaires (I) à $K$ ) ont servi à préciser les extensions des structures romme les variations latérales des stratigraphies.

La slraligraphie globale du site telle qu'elle résultait de toutes les fouilles précédentes, a été confirmée et précisée. L'ancienne falaise bordant le plateau cristallin, aux formes très émoussées, culmine vers $20 \mathrm{~m}$ X.G.F., et sous la butte de Saint-Saturnin le sommet du substratum granitique doit ètre grossièrement sub-horizontal, un peu au-dessous de ce niveau. (on trouve de bas en haut (résultats techniques des analyses sérlimentologiques en appendice) :

le socle granilique, qui peut soit être dégagé et net, soit avoir été concassé par la cryoturbation du dernier grand froid. Dans ce dernier cas. on trouve profondément descendus dans les fentes des résidus de petits galets et de sable, provenant de plages et de dunes très anciennes pouvant remonter au moins au dernier interglaciaire.

Le sol ancien, qui est une arène sableuse humifiée. Il comprend des éléments d'arène du granite sous-jacent mèlés à un apport de sédiment classé, provenant de dunes ou plagres très anciennes: c'est ce qui explique le profil de la courbe granulométrique, la morphoscopie et la présence de minéraux lourds allogènes. La longue pédogénèse post-glaciaire se traduit par une faible teneur en calcaire. Le milieu est très peu favorable à la conservation des os, et les ossements des fosses les plus profondes qui seront venus à son contact sont très altérés. Ce sol ancien contient des éclats de silex, plus rarement des pièces mésolithiques ou néolithiques; celles-ci seront plus nombreuses à l'état remanié au-dessus. Quelques tessons de polerie grossière s'y rencontrent également en place.

La dune inférieure. qui est la première couche importante. pouvant atteindre un bon mètre d'épaisseur. Elle est formée d'un sable brunâtre compact, d'ailleurs plus compact vers le nord, plus meuble vers le sud du site. Ce sable brun est le résultat de l'humification prolongée de la dune, après une pédogénèse progressive el poussée (c'est le sable gris ou la terre grise, ou noire, des anciennes descriptions; le brun correspond davantage aux nuances des codes des couleurs). C'est granulométriquement une dune bien classée quand on prend un échantillon dans la partie méridionale du rectangle $A$ ou dans le rectangle $\mathrm{C}$. avec encore une teneur notable en calcaire (débris de coquilles), et donc favorable à la conservation des os. Vers le nord, tout en devenant plus dure à fouiller, la part de l'arène remaniée du sol ancien devient plus importante et la teneur en calcaire baisse en proportion. C'est cette dune inférieure qui a constitué la formation sur laquelle s'est établi le cimetière a l'origine. et dans laquelle les premières fosses funéraires ont été creusées et recreusées, la brassant sans arrêt. Lille avait dì ètre antérieurement largement remuée par les cultures. La mise en place de cette dune inférieure fut vraisemblablement polycyclique, mais étant donné le brassage qu'elle a subi, on ne peut plus penser y établir une stratiographie significative. Elle renferme des restes archéologiques dispersés dans toute sa masse, allant en définitive du Vésolithique au Gallo-Romain. Les menus tessons de poterie protohistorique ont plus d'affinités avec la poterie d'usage courant du Bronze final et du Hallstatt qu'avec celle de La Tène. Wais on a quand mème recueilli quelques tessons de cette derniere période. Les petits tessons gallo-romains sont surtout en céramique commune, 
il y a aussi de menus fragments d'amphore et de minuscules débris de sigillée. Pour le matériel lithique, il faut signaler un fragment du talon d'une hache-marteau en dolérite, objet perforé du Néolithique final ou de tradition néolithique, trouvé d'ailleurs a la base de la dune inférieure. Parmi les centaines de petits éclats et déchets de silex, il faut mentionner quelques microlithes géométriques bien connus dans le Mésolithique final de la région, notamment quelques trapèzes ; une petite flèche tranchante, plutòt néolithique d'aspect; enfin, un fragment de fleche à ailerons et barbelures du chalcolithique. Comme dans la région on a de nombreux indices de la mise en place éolienne d'une première dune vers l'Âge du Fer, on peut estimer que la masse de la dune inférieure de saintSaturnin est également de cette époque.

La dune supérieure, qui est la deuxième couche d'une puissance au moins égale el parfois nettement supérieure. Elle est formée d'un sable friable, blanc lorsqu'elle n'est pas humifiée. Elle s'est mise en place postérieurement à la principale utilisation du cimetière et recouvre donc les entourages de tombes établis à la surface de la dune inférieure. Mais cette mise en place s'est produite en plusieurs poussées, séparées (lorsque sa masse n'a pas élé perturbée par de nouvelles sépultures) par des petits sols intermédiaires, ces petits sols marquant des temps d'arrêt dans la progression dunaire, l'un d'entre eux étant localement brûlé au surplus. On constate une très forle teneur en calcaire dans la partie la plus épaisse et la moins lessivée, dépassant $50 \%$ (dans d'autres dunes des environs autant ou davantage à l'intérieur des terres, notre collaborateur P. Berrou, auteur d'un travail sur les dunes du sud du Finistère, a trouvé des teneurs de $70 \%$ en calcaire à Tronoan et a Kerviltré, de 5.3\% à l'ouest de Saint--Saturnin, de 59 à $70 \%$ plus au sud et aux mêmes distances de la côte actuelle). C'est un milieu très favorable à la conservation des os, pourvu évidemment que ceux-ci soient à l'abri des racines des plantes et des autres causes de dérangrement. (iranulométrie et morphoscopie témoignent de l'origine du sable, avec toutefois un transport assez faible : de même que de nos jours le littoral n'était pas loin. La base est moins purement dunaire. L'analyse des petits sols intermédiaires témoigne d'une décalcification pédogénétique.

Le sommet de la dune supérieure constitue le sol actuel; l'épaisseur de rette altération est. variable selon les points. Ces terrains étaient encore cultivés il y a 25 ans. Ia culture a forcément nivelé le terrain et fait disparaitre depuis longtemps les dernières traces de la topographie dunaire. Celles-ci subsistent au-delà des limites du cimetière de Saint-saturnin, el dans des \%ones éparornées par la culture, par exemple au nord-est de la parcelle 47.

La morphologie actuelle du terrain et les profondeurs peuvent être tress différentes des situations successives anciennes, encore que le profil de la surface actuelle de la dune supérieure soit à peu près parallèle à la surface de la dune inférieure.

Le massif de ruines et de blocages avait été arasé anciennement, avec récupération de la plupart des pierres des maçonneries, pour se fondre dans la topographie d'ensemble. Mais dans tout le secteur correspondant au sommet du tertre, vers le milieu de la carrière, et à la partie occidentale des fouilles tant anciennes qu'actuelles, le sommet de la stratigraphie était compliqué par un apport supplémentaire complexe, qui semble d'ailleurs avoir été la cause d'un bombement accentué du relief visible sur d'anciennes photographies. La dune supérieure y était surmontée et parfois tronquée par cet apport qui comprenait de la terre, du sable, de la caillasse, de l'argile, etc., en niveaux successifs hétérogènes et fort différents selon les points. Il est naturel de voir dans cette addition les déblais provenant des phases successives de l'extension des décapages nécessaires à l'exploitation de la carrière au cours des temps. Ces déblais auront incorporé des matériaux provenant de l'arasement, de la partie nord du massif de ruines et de blocage. Dans la zone occidentale des fouilles de 1920 à 1924 ces déblais se superposaient au cimetière (et c'est ainsi qu'il faut réinterpréter les coupes publiées). Lors des travaux de 1946 à 1950 comme de 1973 à 1975 nous n'avons plus eu à observer cette situation au-dessus du cimetière proprement dit, car les restes décroissants de ces apports se superposaient au massif de ruines et de blocaille et à ses abords occidentaux. 


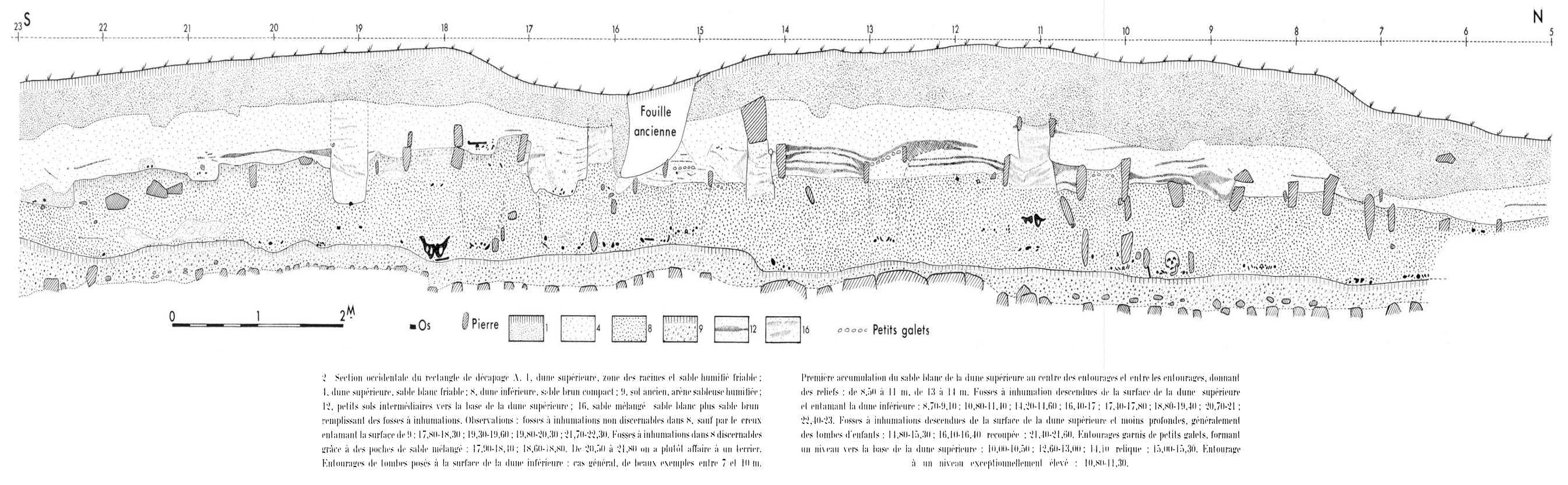




\section{Le cimelière proprement dit.}

En ce qui concernait les inhumations, il semblait résulter des fouilles anterieures que la dune inférieure contenait deux ou trois niveaux de squelettes, le niveau le plus profond ayant seulement été observé au nord du site lors des premières explorations de 1920 à 1924. Les deux niveaux suivants, superposés l'un sur l'autre vers le haut de la formation. le dernier correspondait aux entourages de tombes, les seuls complets parfois, construits à la surface du sable brun compact. Nais on avait remarqué que ces entourages se trouvaient sourent dans la curieuse situation d'ètre très soigneusement aménagés, tout en n’ètant pas fonctionnels et ne correspondant à aucune inhumation sous-jacente.

De même, il semblait que dans la dune supérieure on pouvait distinguer trois niveaux de sépultures. A sa base on trouvait des tombes hàtivement installées, les squelettes étant coincés entre les entourages dépassant alt-dessus de la surface du sable brun, ou mis dans des fosses creusées dans ce dernier. fosses aisement distinguées car elles étaient remplies d'un panachage de sable brun et de sable blanc. P'uis à quelque hauteur dans le sable blanc, on avait des tombes à entourages en très bon état et soignés, souvent à couverture de petits galets de quartz; cependant ici encore, on avait constaté que ces entourages etaient rarement fonctionnels. Enfin, de nouveau. à faible profondeur par rapport à la surface du sol actuel, on avait un dernier niveau de sépultures peu soignées, des squelettes enterrés sans aucune trace de structures d'accompagnement.

On avait donc eu tendance à comptabiliser comme niveaux de sépultures, à la fois les inhumations, les squelettes eux-mêmes et les pierres qui pouvaient parfois être disposées autour, et d'autre part les entourages de galets encadrant la surface d'une sépulture au niveau du sol. Ceci parce qu'on avait vu un certain nombre de cas où l'entourage paraissait directement superposé, à 10 ou $20 \mathrm{~cm}$ au-dessus du sujet. Et notamment on etait impressionné par les rares cas de tombes en ciste qui avaient été remarqués dans la partie nord du cimetière. P. Ju (hâtellier notait que "la plupart des squelettes etaient directement en terre ", mais « un seul était enfermé dans un coffre formé de pierres posées de champ en terre, recouvertes de pierres plates". Les fouilleurs de 1922 avaient trouve un cas exeptionnel de: ciste trapézö̈dal à deux squelettes, recouvert de morceaux plats de micaschiste bleu.

Fouiller en milieu sableux dans une région éventée non loin du bord de mer est diflicile, sans: aucune protection contre le dessèchement comme contre la pluie. L'idéal est de travailler sous abri, mais on ne comprend bien un cimetière que si l'on en dégage une assez large surface à la fois, théoriquement il faudrait pouvoir en fouiller la totalité. Il a fallu se contenter de travailler par décapage de rectangles dont la largeur correspondait à la largeur utile maximum des bàches plastiques disponibles, qui étaient redéployées pour protéger structures et squelettes en fin de journée ou en fin de période de travail.

Le grand rectangle $A$, décapé dans le cimetière en 1973-1974, avait pour dimensions principales $18 \mathrm{~m}$ nord-sud et $4 \mathrm{~m}$ est-ouest, avec quelques dépassements localisés rendus nécessaires par l'état des choses. Sa largeur fut portée a 5 m avec le décapage de la bande irrégulière le séparant de la limite des anciennes fouilles, et le jalonnement approximatif des raccordements avec relles-la. Le rectangle $\mathrm{C}$, décapé dans le cimetiere en 1975 , avait pour dimensions principales $6,50 \mathrm{~m}$ nord-sud et $6 \mathrm{~m}$ est-ouest, avec les dépassements. 


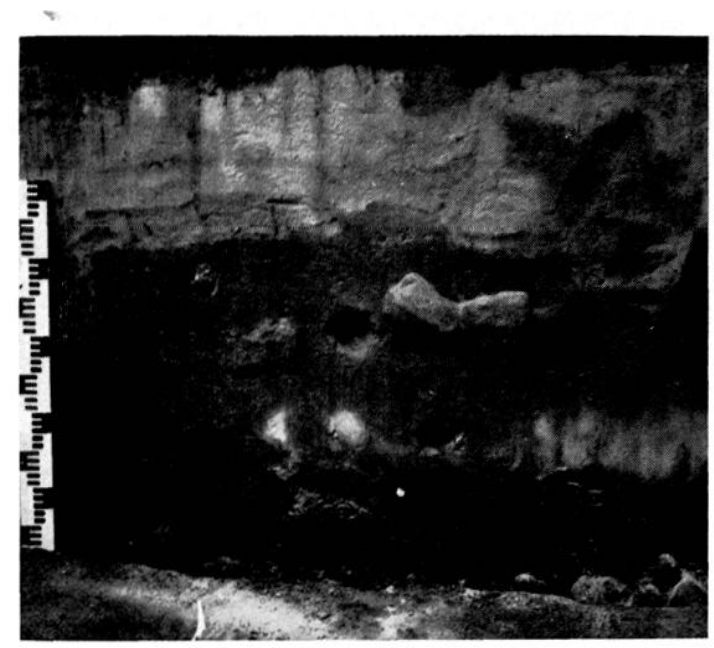

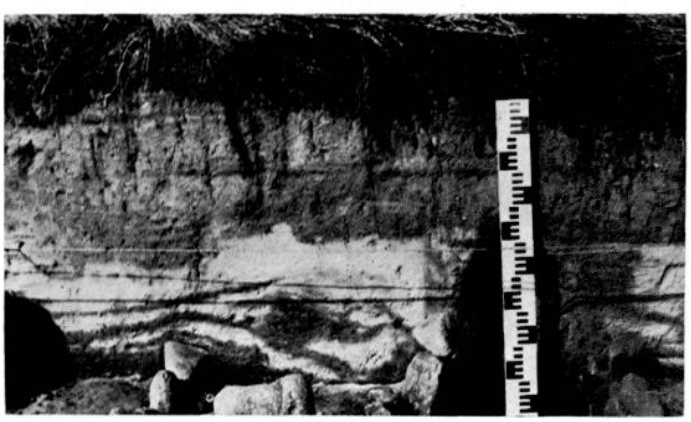

1 Seclion occidentale du rectangle de decapage I entere $x$ el $10 \mathrm{~m}$. ()n dislingue a la base de la dume superierure blanche, a gauche, des pelits sols inlerme-

diajres. inferrompus at droile par des fosses.

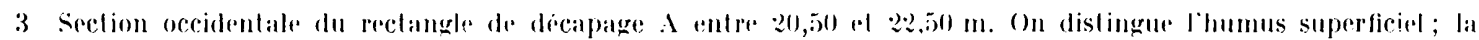
dune superieure banche arec des restes de sols intermediaires, interrompus de droile par une fosse de tombe; la dune inferienere foncere, interrompur it droile par des fosses remaniant des pierres dentourages et des panachages de sable banc donc des lombes de la sirie recente mais descendues forl bas ; le sol ancien ren tres fonce od les pierres du fond.

Le commentaire de la seretion nord-sud (fig. : a a 4 ), relevée sur la paroi occidentale du rectangle A, comme celui de la section nord-sud relevée sur la paroi est (fig. b) du rectangle (d, permet de synthétiser l'ensemble des observations nouvelles qui ont été faites sur le detail de la stratigraphie, de la chronologie relative et du mode de fonctionnement du rimetière. En développant la dénomination de "néropole à étages ", les premiers fouilleurs de 1920-1924 pensaient qu'ils avaient observe plusieurs rourches d'inhumations distinctes dans le sable brun compact de la dune inférieure, cette formation s'étant pour eux mise an place en trois assises ligemement, differentes, daqque squelette étant en somme pose au fond d'une fosse relativement peu profonde. Ce sera notre principale divergence d'interprétation. les observations des premiers fouilleurs ayant été dans l'ensemble fort bien faites pour l'époque, et ce sera aussi la principale rectificalion de notre exposé de 1951. Les fouilles de 1946 à 1950 nous avaient laissé penser qu il pouvait se trouver dans le sable brun compact un niveau inférieur de lombes assez frustes : nous serons plus radicaux aujourl'hui et nous pouvons affirmer que toutes les sépultures se trouvant incluses dans cette dune inférieure ont été déposées au fond d'une fosse, plus ou moins profondément creusée à partir de la surface de l'époque. Creusées et remplies du mème terrain homogène, ces fosses ne se lisent gurre sur le terrain. Plus d'une a recoupé et dérangé une sépulture préexistante, de sorte que les ossements du premier occupant se retrouvent mélangés dans le remplissage entourant ou recouvant le nouvel occupant qui lui, est resté en connexion anatomique.

D'une manière générale la surface de la dune inférieure est garnie d'un ensemble d'entourages de tombes, les uns intacts, les autres antérieurs et diversement respectés ou ruinés (fig. 6 et 7). (On est conduit à conclure que le cimetière al fonctionné pendant un temps appréciable sinon fort long pendant cotte premiere phase. Il est difficile de supputer chez ces populations le temps qu'une tombe prenait en moyenne arant de passer dansl'oubli (il n'y arait pas de 


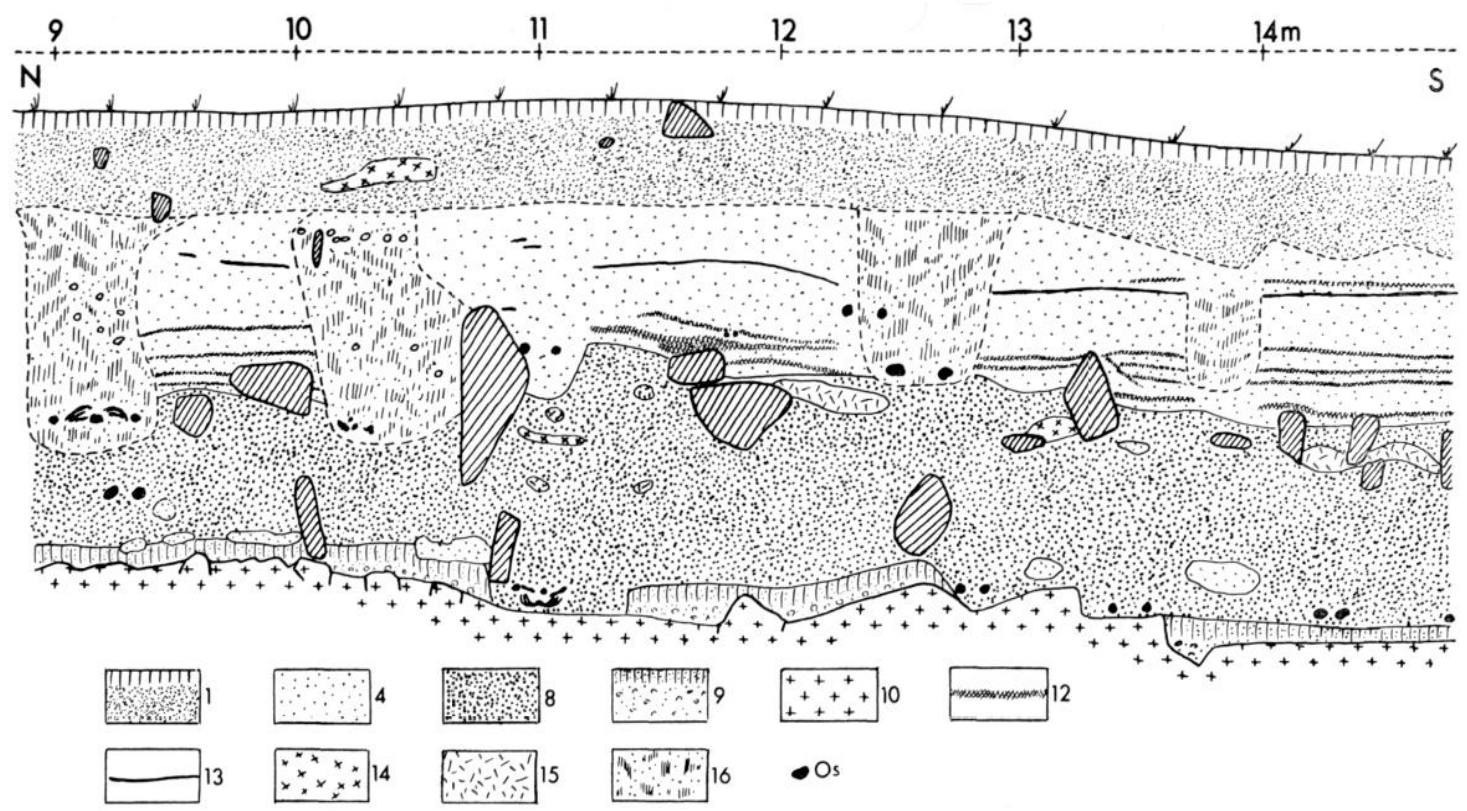

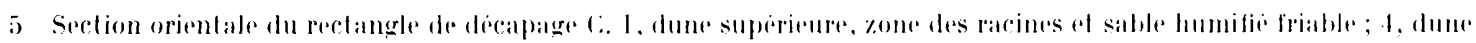

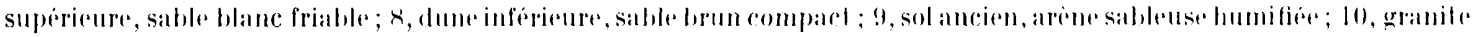

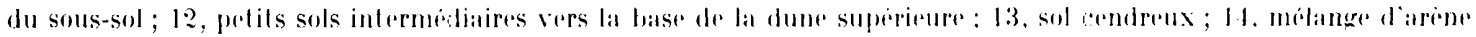

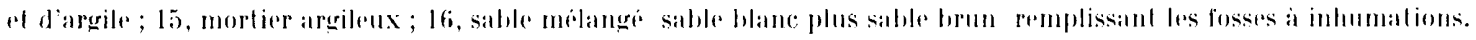

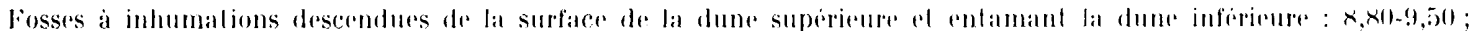

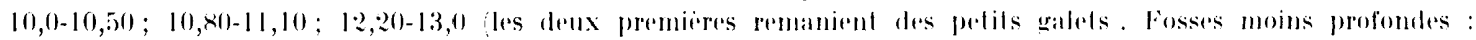
$12,2(1-12,40$ coupe (n) hiais : 13,65)-11,0.

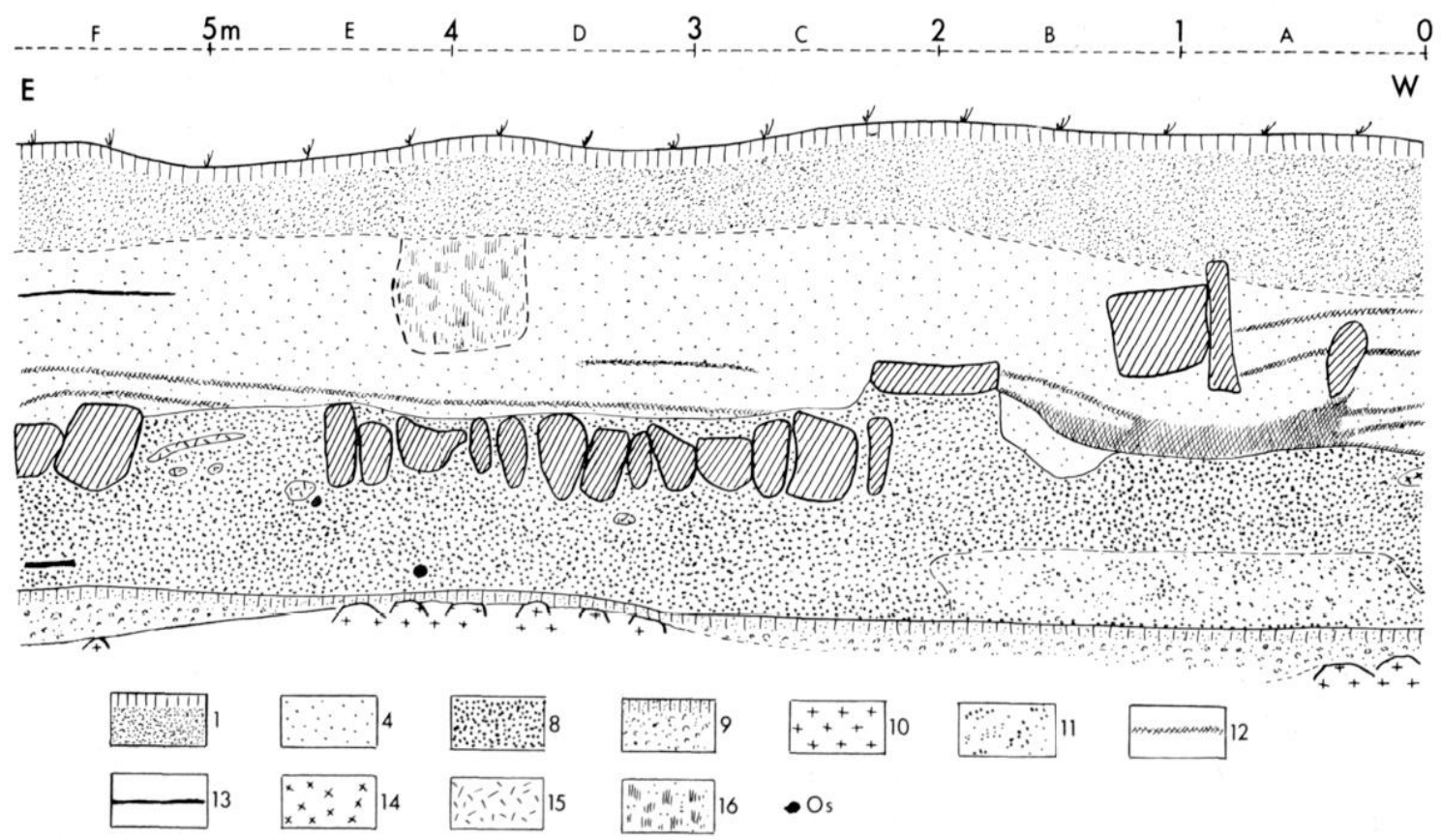

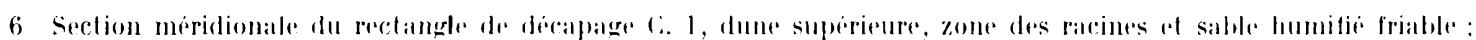

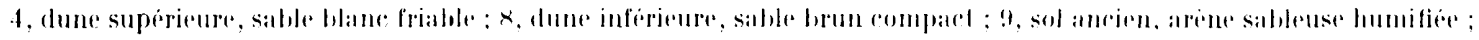
10, granite du sous-son; 11 , sable melange blane ol brun: 12, petits sols inlermediames vers la base de la dume

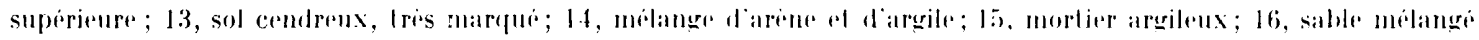

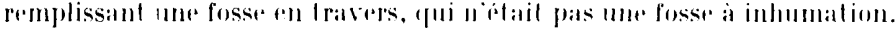


"concessions à temps), mais au vu de la densité des inhumations successives, on peut se risquer à suggérer une durée daretivite minimale de l'ordre de quelques générations. et probablement de beaucoup plus.

Less inhumations dans le sable brun compact de la dune inférieure ont eu lieu, pour une part, lors d'une longue phase ou la surface du sol abait celle de cette formation, en remaniement local incessant lors des inhumations et travaux sueressifs : le remplissage des fosses reste homogène. Ces inhumations constituent une premiere et longue série d'utilisations du cimetière, une première phase.

Mais une deuxieme phase a fait suite alors que de faibles couches de sable blane de la dune supérieure s'étaient déja mises en place, formant la base de la dune supérieure. On peut même se poser la question de sarcoir si parfois, alu moins localement, ces couches n'ont pas été apportées, mais il est plus vaisemblable de penser à un apport éolien, à des tempètes de sable venant d'un cordon dunaire se rapprochant peu à peu, suivies de régalages plus ou moins soignés. Les tombes de cette phase viennent toujours se creuser dans la masse de la dune inférieure, et la profondeur des fosises n'est pas un critere chronologique. Elles se reconnaissent à ce que, dans le remplissage des fosses, s'intercalent quelques pelletérs. poignées ou infiltrations de sable blane produisant un panarehage. Et les entourages des tombes. construits dabord all-dessus du niveau du sable brun vont jusqu'a se trouver édifies sur des rourhes de sable blane plus ou moins épaisses. 11 y a des dessus de tombes construits sur des surfaces inclinés. mais il y a aussi des effels de tassement irrégulier et d'éculement latéral, on n'est plus en milieu stable cette continuation de l'utilisation du cimetière. sous des conditions iecologiques rommencant à changer, nous semble n'aroir duré que quelques dizaines d'année's, une, deux ou trois générations.

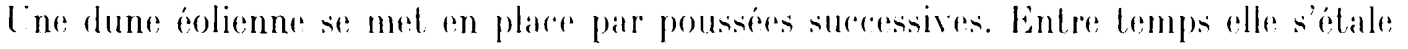
par le ruissellement, l’eboulement et les agents les plus divers, dont les régalages intentionnels qui semblent avoir jour ici. La dune peut se fixer par une végetation et de pretits sols peurent trourer le temps de se former. Les anciens fouilleurs avaient remarqué aree perspicarité, dans leur zone de tratail. quat re de ces traces d'humus dont ils alvaient pent-itre un peu schématisé la constance. Sous les avons retrouvers moins universelles, en 1946-

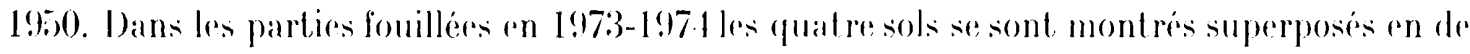
petites fractions de coupes, et ailleurs perturbes ou subsistant a l'etat de reliques. sur les sections du rectangle (' fouille en 1975) (fiz. i)). on trouve localement jusqu'à cing ou six de ces sols intermédiaires, dont l'un est brùlé.

Les tombes de cedte seconde phase de fréquentation du rimetière présentent des entourages de surface correspondant a peru pres à l'un ou l'autre de ces sols intermédiaires (fig. 8 et 9). Elles peuvent ou non presenter une garniture interne de petits qaalets. Au total il n'y en a pas beaucoup d'un niveau déterminé.

Cne plus grande masse de la dune supérieure s'est ensuitr mise en place d'un coup. Elle a ele traversee par une série de fosses a inhumations assez clairement lisibles, corres-

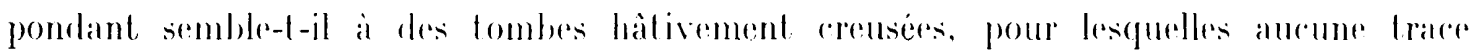
d'entourage n a été rencontré pres de la surface artuelle sur le perimetre des foulles surecessives. Mème si les travaux agrieoles avaient au cours des siecles arraché la plupart de ces 


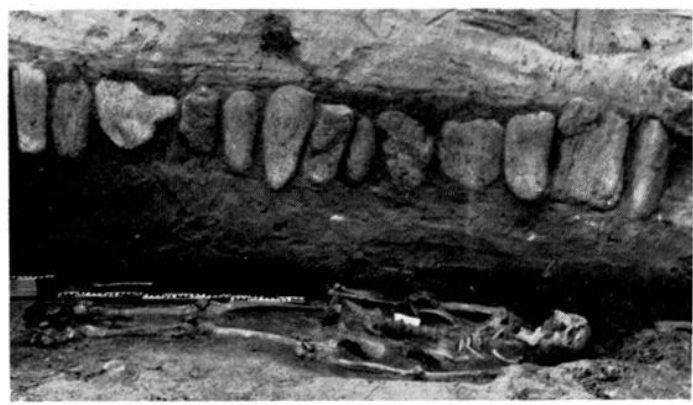

7 Section meridionale du recelangle c. Correspondance

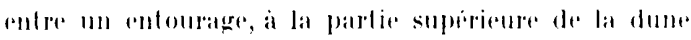

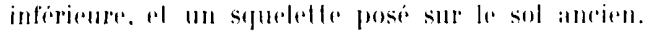

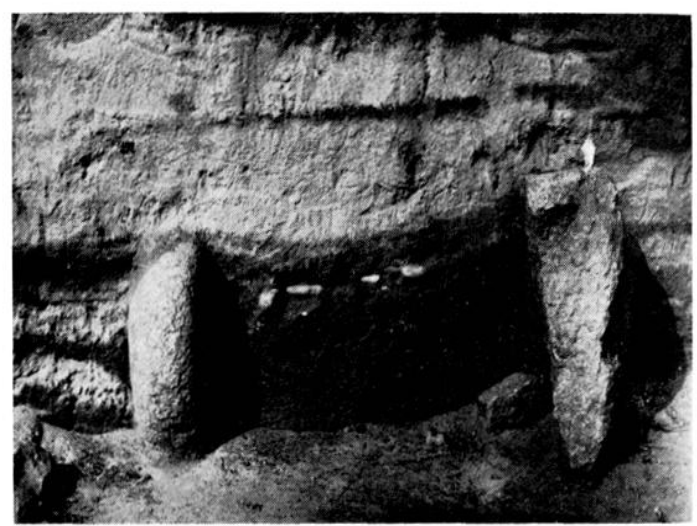

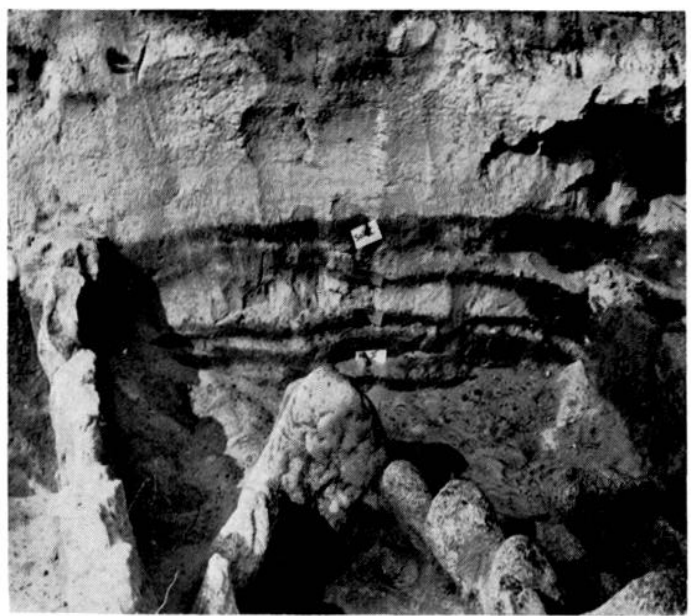

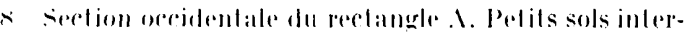

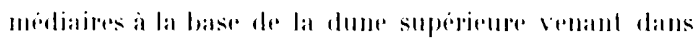

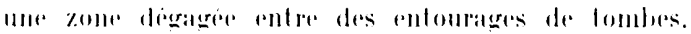

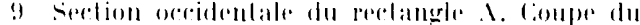
remplissige doun entourage dr lomber alrec lit de pelits galels. la remplissage est formi de sable de la dune inferienere extrail de la fosse en remis. (On roil $a$

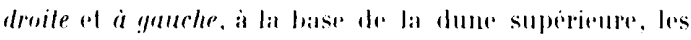
pertils sols inlermediaires, of on constale que le sommel

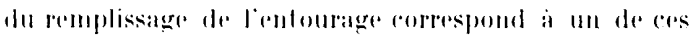
sols.
}

pierres d'entourages et nivelí tout. il en serail peut-ètre restes sullisamment de pelites dimensions pour garder un somsenir partiel des tombes de cetle trobisme ot ultime phase. bien entendu le sommet de la dune superieure, du fait de la pédogenese, montre une oblitération des traces de fosses et de remanioments divers.

si l'on considere les choses en plan, au nivean des delails on a confirmé les constalations des fouilles précédentes et nous y insisterons moins. Ies mort sétaient normalement enterés en décubitus dorsal, en position adaptee a la fosse el aux obstacles rencontrés lors du creusement de celle-ci. Bien entendu chaque sépulture a fait l'objel d'un releve individuel.

Les utilisations tardives de la troisieme phase s'étaient marquées lors des fouilles précédentes par des inhumations a tries fable profondeur, en ordre négligé aver des squelettes dans des positions inhabituelles. On en a retrouvé des exemples an surl-ouest du rectangle 1 . Dinsi deux squelettes superposes, relui d'en dessus dant tout a fail en desordre fee qui indiquerait que c'est un sujet. sorti lors du reusement de la fosie, dont les os ont ele remis all-dessus du radare). celui d'en dessous, a environ 0.75 m sous la surface artuelle, etanl en lailleur. Dans le rectangle $G$ on a eu le cas d'un sujet sans ràne, et dont les jambes chaient déviees vers la gaurhe. W'une maniere générale ces inhumations lardives ont des orientations beauroup plus variables, pouvant devier dans un sens comme dans l'autre jusqu'a 300 fig. 10.11 el $12 \%$

Pour les sépultures a peu pris réqulieres, on peut noter que les avant-bras sont le plus souvent alignes le long du corps. les mains etant appuveses sur le haut des fémurs et les poignets sur le bord des ilions. re qui apres déomposition dome des silualions de delail asse\% varies. Mais également tris souvent les avant-bras sont en oblique el les mains aroisiess sur le pubis. Il existe des sujets 


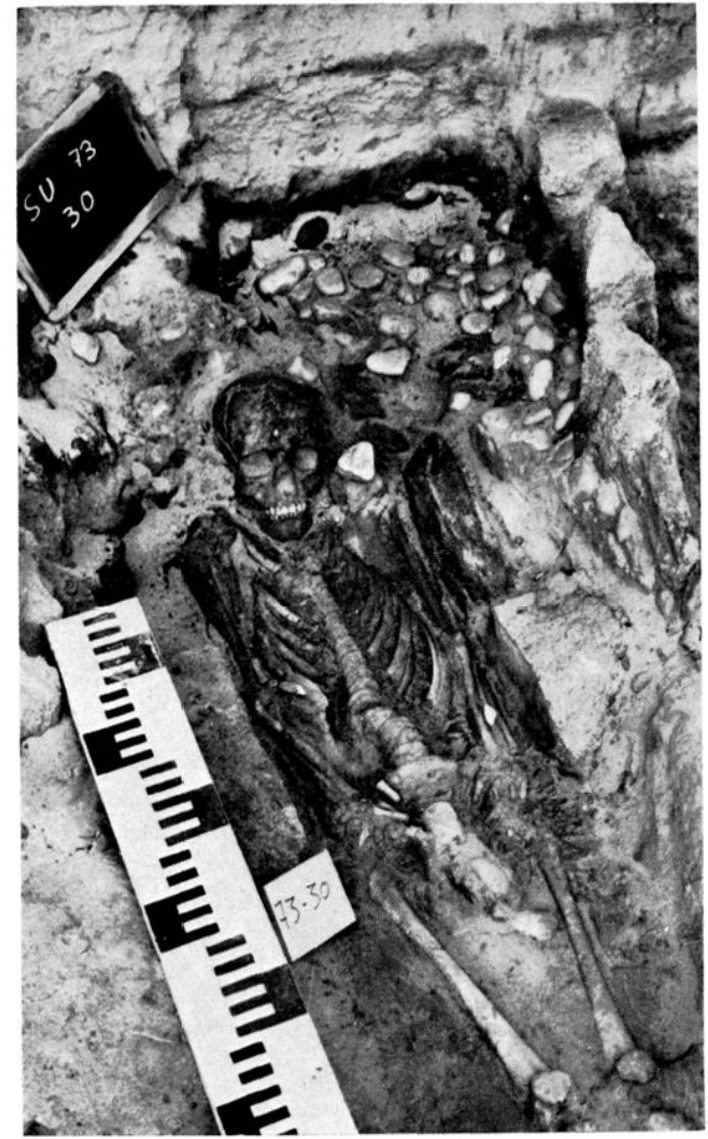

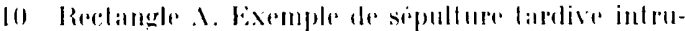
sive vellue derangere une couverture a pelils galdets diun inlourage.

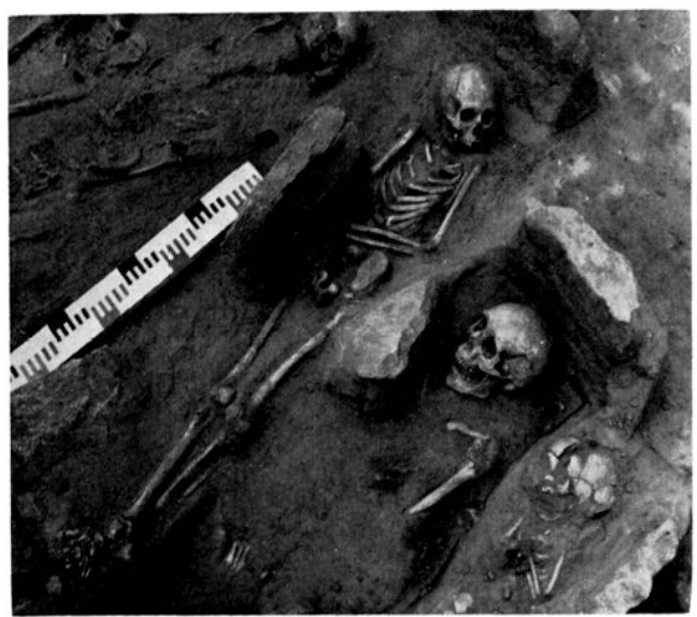

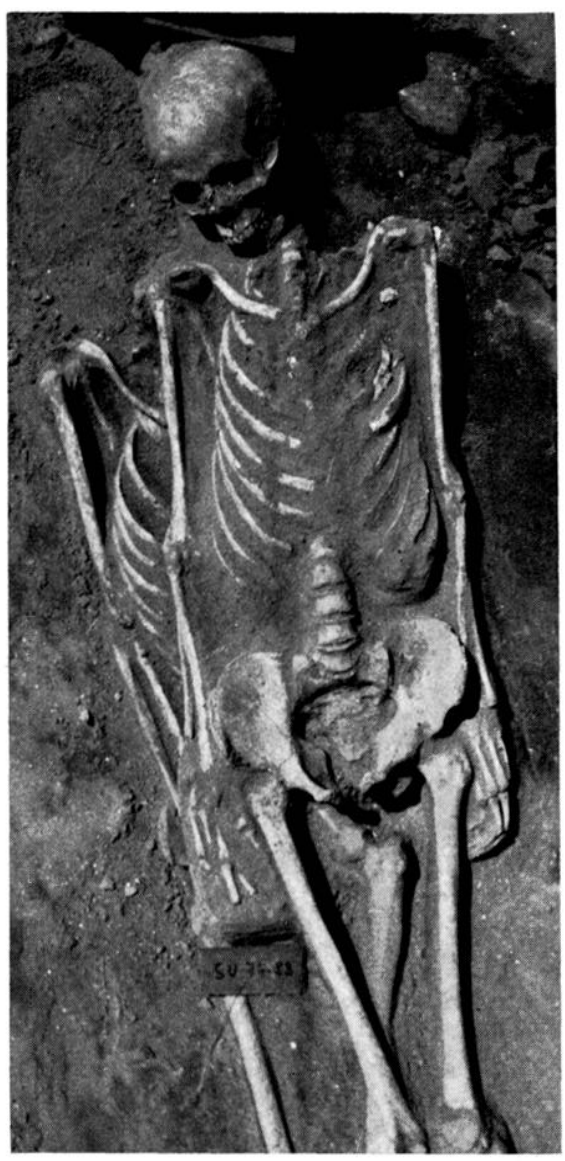

11 Rectangle A. Hexpmpte de deux inhumalions prat ieperment l'ume antedessus de l'autre.

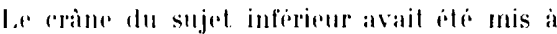
sis pirils.

- 1: Rechangle t:. Eximple dencastremont den sujel resserro entre les piereses bordant les fosses a inhumations anterieures. 


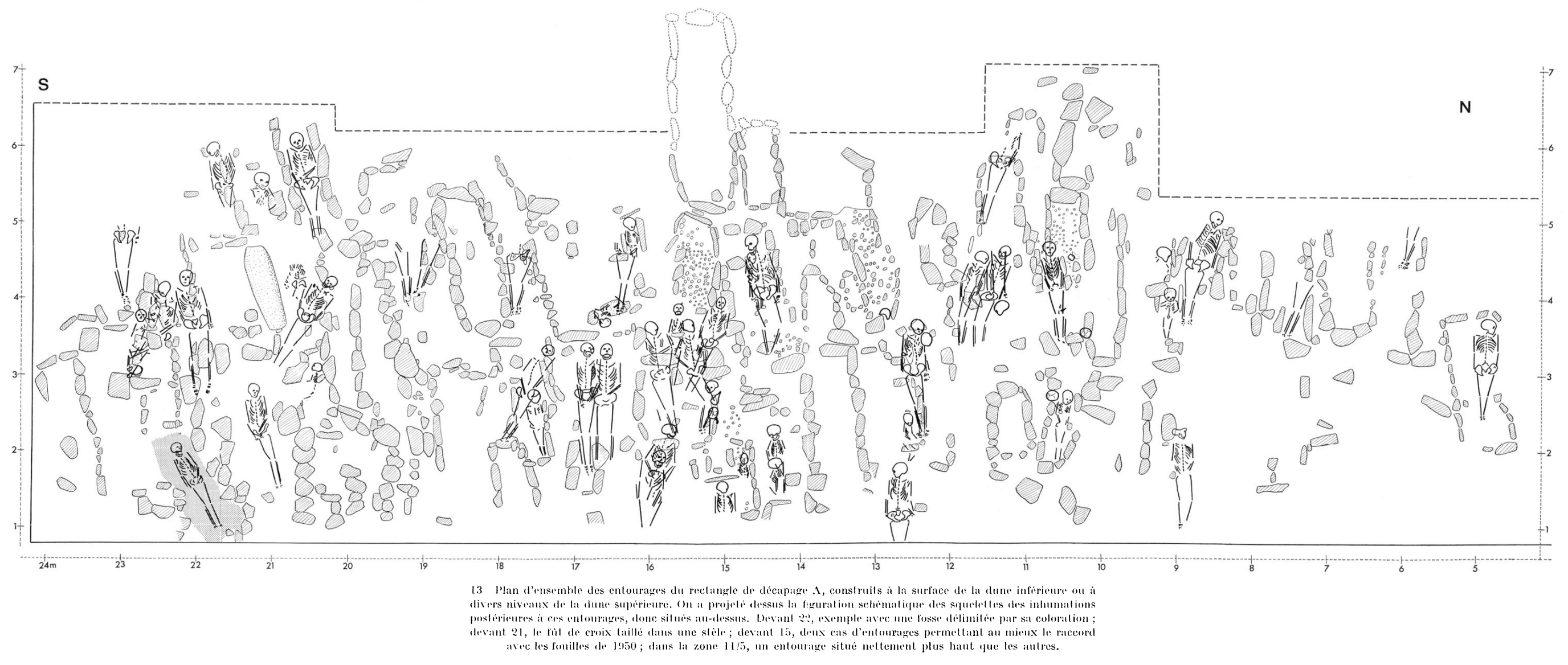


aver un avant-bras dans une disposition et l'autre dans l'autre. Dans des cals plus rares. la main droite enserre le poignet gauche. ou réciproquement. Il y a aussi quelques bras croisés à angle droit; tout a fait exceptionnelle est la posture aver une main sur l'épaule opposée.

Les pieds peuvent òtre étendus còte ì còte. ou ìtre rassemblés. On a rencontré de triss rares cas de jambes croisées. Dans le cas des sépultures d'enfants les positions sont beaucoup plus variables. Ce sont surtout celles-ci qui ont été souvent un peu tassóes dans une fosse trop étroite, coincée entre des structures préexistantes que l'on n'aura pas beaucoup détruites.

Les entourages rectangulaires. construils en principe au-dessus des tombes, sont de dimensions et de réqularité trís variables; d'ailleurs beaucoup ont été dérangés par des sépultures adventices. Les galets marins sur champ y jouent un ròle majeur. à cóté de blocs de granite. On a quelques cas où l'entouragre principal de pierres verticales est dédoublé par un systeme de pierres posées à plat à un niveau un peu plus profond, réalisant des sépultures tress soignées. Les pierres têtières, sortes de stèles un peu plus hautes que les autres pierres des entourages. sont fréquentes mais pas constantes (fig. 15). 16 et 17 ).

La juxtaposition des entourages sur des plans d'ensemble /fig. 1:3 et 14/ montre combien souvent ils ont servi de source de matériaux pour de nouvelles tombes. tout en laissint voir par plares une meilleure organisation des sépultures les unes à còté des autres. C'est ainsi que dans le rectangle 1 la partie médiane est asse\% bien disposée. quoique re soit la zone ou sont venues s'ajouter la plupart des tombes à couverture en petits galets. Dans la partie orientale du rertangle $\mathrm{C}$ on a mème l'impression d'un alignement concerté de l'extrémité de quelques tombes en respertant une ruelle nord-sud, malgré quelques résidus de pierres parasites plus profondément enfoncées. Par souci de ne pas multiplier les documents, nos plans d'ensemble projettent còte à còte des entourages et pierres diverses rencontrés lors du décapagre successif de 0.40 à $0.50 \mathrm{~m}$ de matériaux. c'e qui a tendance à accentuer malheureusement l'impression d'encombrement.

On a projeté sur ces plans d'ensemble des entouragres (figr. 1:3). le figuré schématisé de l'emplacement des squelettes de la derniere el troisieme phase des enterrements - inhumés à partir de la surface de la dune supérieure - pour bien montrer leur discordance générale par rapport au système des entourages, et l'on voit que souvent le creusement de leur fosse est responsable des lacunes des entourages, lant ceux des niveaux a petits galets que ceux du niveau principal établi a la surface de la dune inférieure. On voit des exemples d'encastrement des corps entre deux rangées de pierres d'entourages, ou contre une seule rangée, au hasard des positions des fosses.

Cn deuxieme jeu de plans d'ensemble (fip. 18 et 19) fignure les pierres trouvées sous la surface de la dune inférieure, et les emplacements des squelettes des premiere et deuxieme phases des enterrements. Au niveau des sépultures les plus profondes il fut possible de grarder quelque temps en place presque toutes les inhumations, au cours de chaque campagne de fouilles. de maniere a pouvoir prendre des photographies d'ensemble el faire des comparaisons.

Grâce aux coordonnées. il est possible de comparer les situations des entouragres figurés sur les premiers jeux de plans, el celles des squelettes dessinés schématiquement sur le second jeu. Nous avons bien entendu travaillé au laboratoire par superpositions des calques. On voil la rareté de la correspondance entre la position exacte d'un squelelte et celle des entourages situés a son voisinage au-dessus de lui, bien qu'il y en ait des cas. Il y a généralement un décalage entre la fosse funéraire et la structure de tombe construite ultérieurement a la surface. Tout simplement peut-être n'attachait-on pas une tres grande importance a la correspondance topographique entre le cadavre et la tombe qui le matérialisait en surface du sol consacré. (On peut vérifier que bon nombre des entourages ne correspondent mème pas à des enterrements effectifs. Il y a la évidemment un problème, et un aussi grand nombre de cénotaphes s'expliquerait mal. On est ramené à la remarque précédente.

Par contre le phénomine de la réulilisation approximative des mèmes emplacements pour les fosses des sépultures peut ètre analysé. Il y a en grénéral un léger décalage. de sorte que le premier occupant peut ètre coupé en long ou en travers. I'autres fois, la première sépulture est a peu pris 


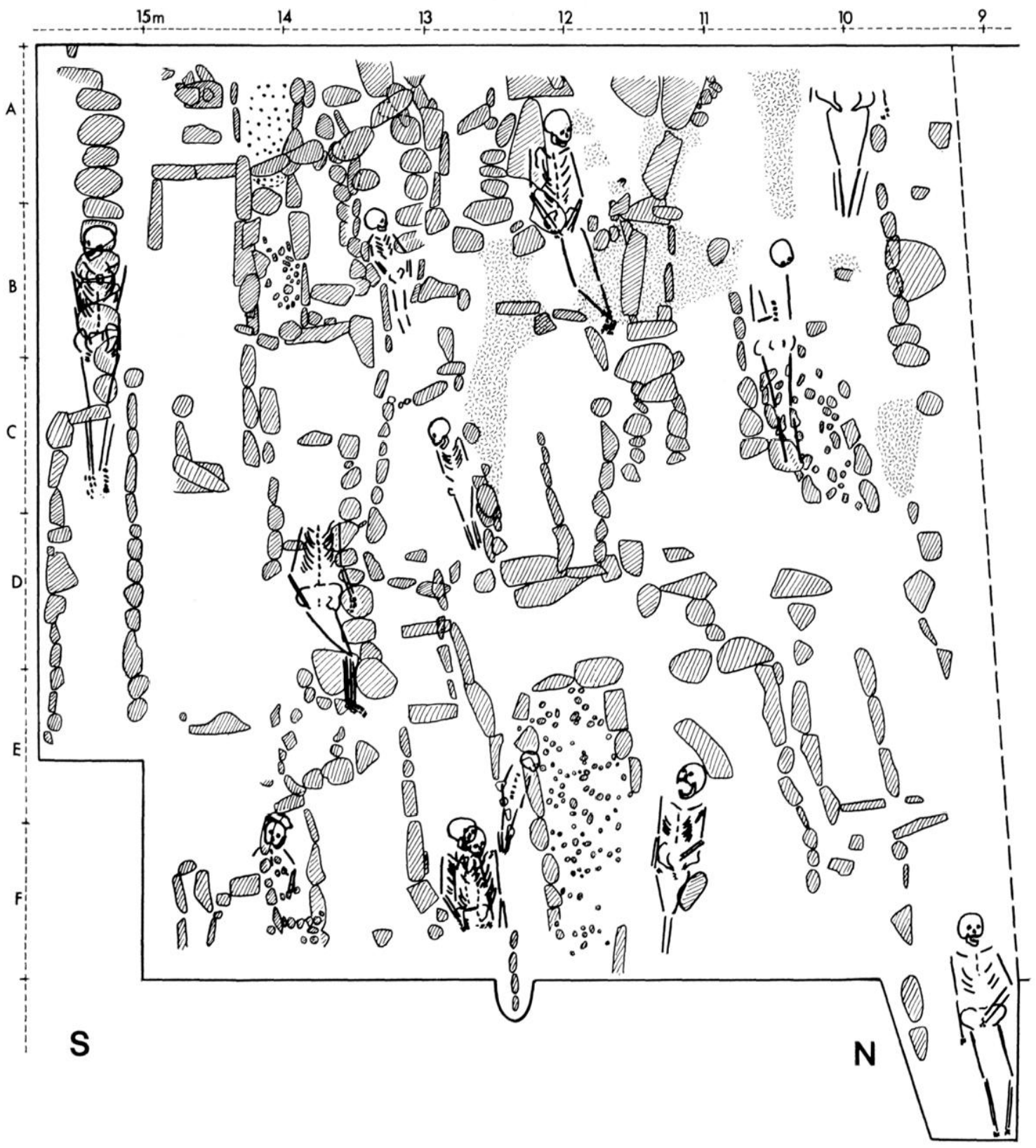

1.t Plan densemble des entourages du rectangle de decapage ca, construits a la surface de la dune inférieure ou à divers niveaux de la dune superieure. ()n a projete dessus la figuration schematique des squeleftes des inhumations posterieures à ces entourages, donc situes au-dessus. En tramé des masses de mortier argileux venant jusqu'au niveau des entourages. I a ligne tirete a droite schematise la limite des chantiers ta et B, le bord du "mur meridional ". En surface, tout le long de ce mur et dans loute la zone nord-ouest, importante epaisseur de materiaux divers de blocage of d'eboulis. En position 10,50/B-C, le squeletle d'un sujel inhumé tres haut, dans la masse des blocages. 


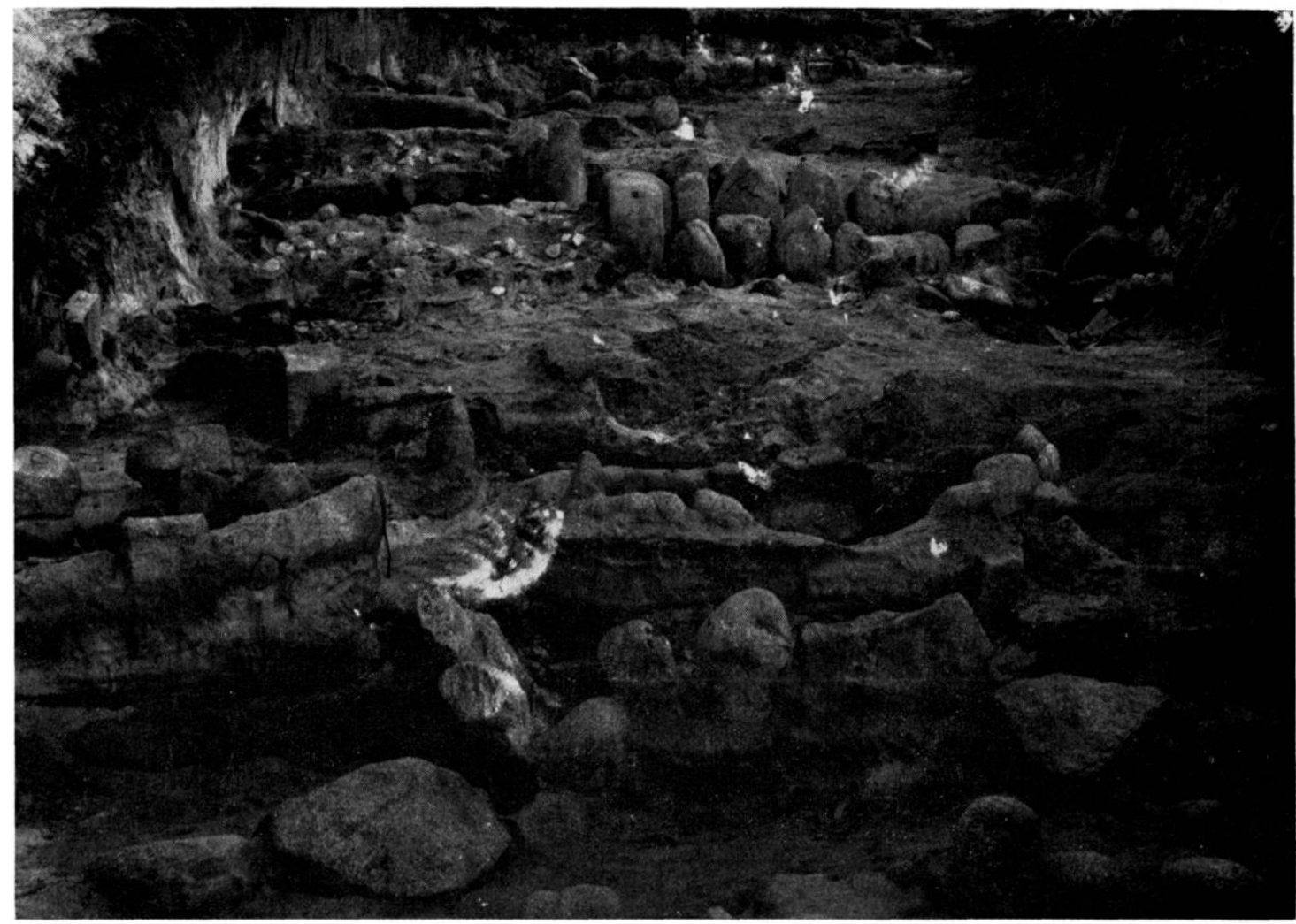

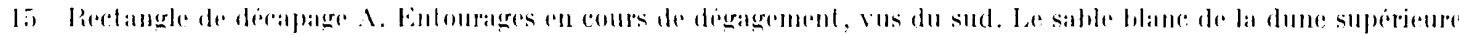

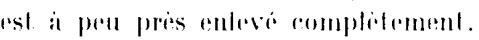

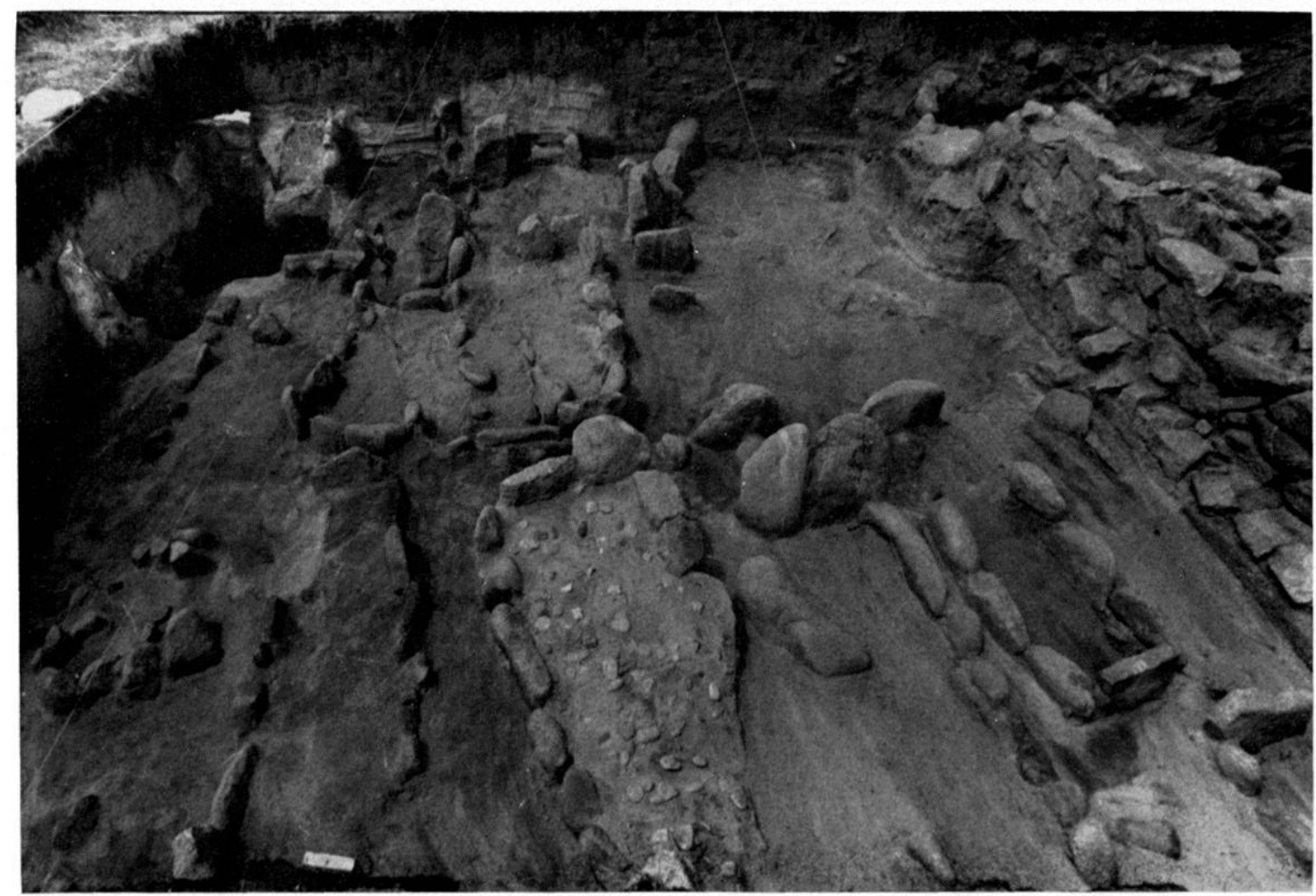

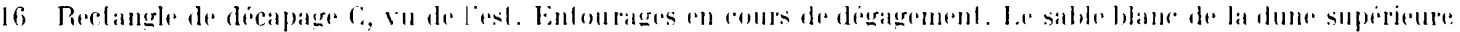

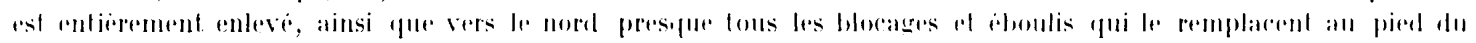

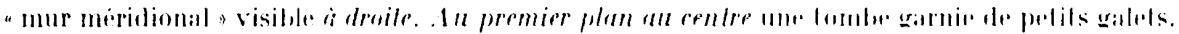




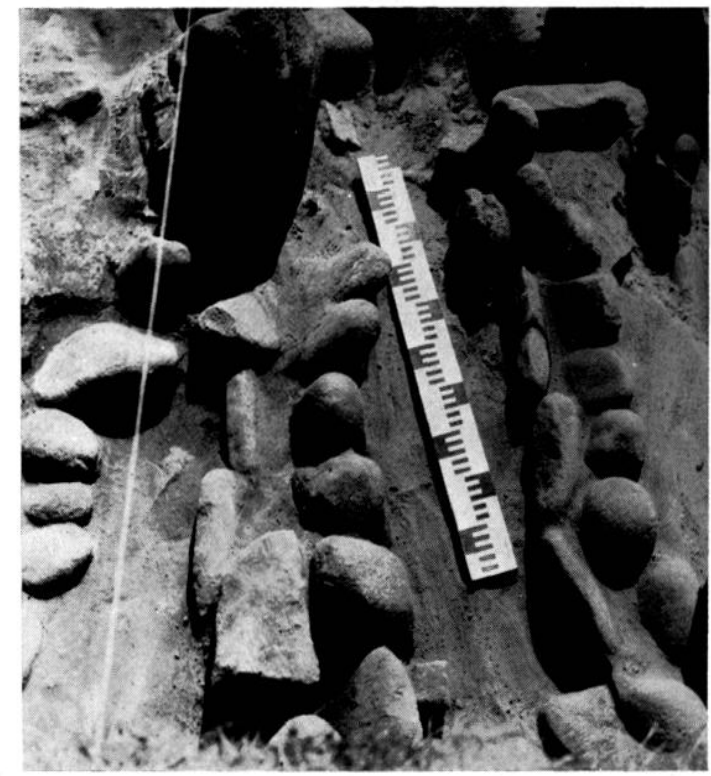

17 Reclangle de décapage c: Rerail de juxtapositions dientourages.

restée en place, a part le cràne, trop encombrant. Le crane a pu itre mis aux pieds du nouvel arrivant, ou enterré isolément à còlé, de sorte que l'on trouve a la fouille d'un còté un squelelte sans cràne, et de l'autre un cràne seul. Il est des sépultures où l'on a rencontré, auprès de la tète du nouvel occupant, deux ou trois crànes, d'ailleurs en maurais état, de sujets jeunes.

Enfin, une autre pratique a été celle du paquel d'os, assez correctement disposé, qui est mis dans le coin d'une nouvelle fosse (fig. 21). Dans un ras nous avons rencontre deux paquets, de part. et d'autre des restes du nouveau squeletle. Dans un autre le panuel d'os se trouvait plus profondement, sous les jambes du nouvel occupant (fig. 22). Ces paquets d'os sont les restes, ainsi stratigraphiquement déterminables, des plus anciennes sépultures inslallées sur re site.

D'un autre côté, il est à remarquer qu'au niveau du fond il restail pas mal d'espaces ou d'emplacements potentiels qui n'ont pas été occupés par des sépultures anciennes. celles de la première phase. Ils auront pu l'ètre en général un peu moins profondément, par des sépultures plus récentes. Mais les sépultures les plus profondes atteignant un sable plus riche en arene remaniée du sol ancien, ou venant jusqu'à reposer sur celui-ci, les ossements peuvent s'y trouver beaucoup moins bien conservés. En particulier, ceux des enfants auront pu se dissoudre sans laisser de traces.

La mise en place de pierres autour du défunt, figurant plus ou moins un cercueil, ou limitée à une pierre à la tète et aux pieds, n'était pas une pratique générale, même si l'on tient comple du fait que, dans quelques cas, les paquets d'os provenant des prédécesseurs en tenaient un peu lieu. Il y a cependant quelques fosses avec des garnitures de pierres autour du squelette assez soigneusement disposées; malheureusement presque toutes ces garnitures auront été au moins sur un colé dégradées par une inhumation postérieure et voisine. La plupart des pierres isolées ou déconnectées des plans généraux au fond seront soit des pierres errantes soit des pierres d'entourages détruits tombées avec les matériaux de remplissage d'une fosse.

Mais nous avons eu une surprise : c'est l'utilisalion d'ossements de baleine comme garniture de tombes. Comme l'échouage des cétacés sur nos còtes était jadis un phénoméne assez fréquent. il n'est pas étonnant que les populations littorales aient pu exploiter i des fins diverses ces réritables mines. En dehors de quelques sépultures, tant dans le rectangle A que dans le rectangle $\mathrm{C}$, où les traces d'os étaient si minimes qu'on peut tout juste en mentionner la présence, on doit signaler dans le rectangle $A$ deux sépultures d'adultes avec des garnilures latérales taillées dans des grands os (figr. 23) qui ne peuvent venir que de cétacés. 


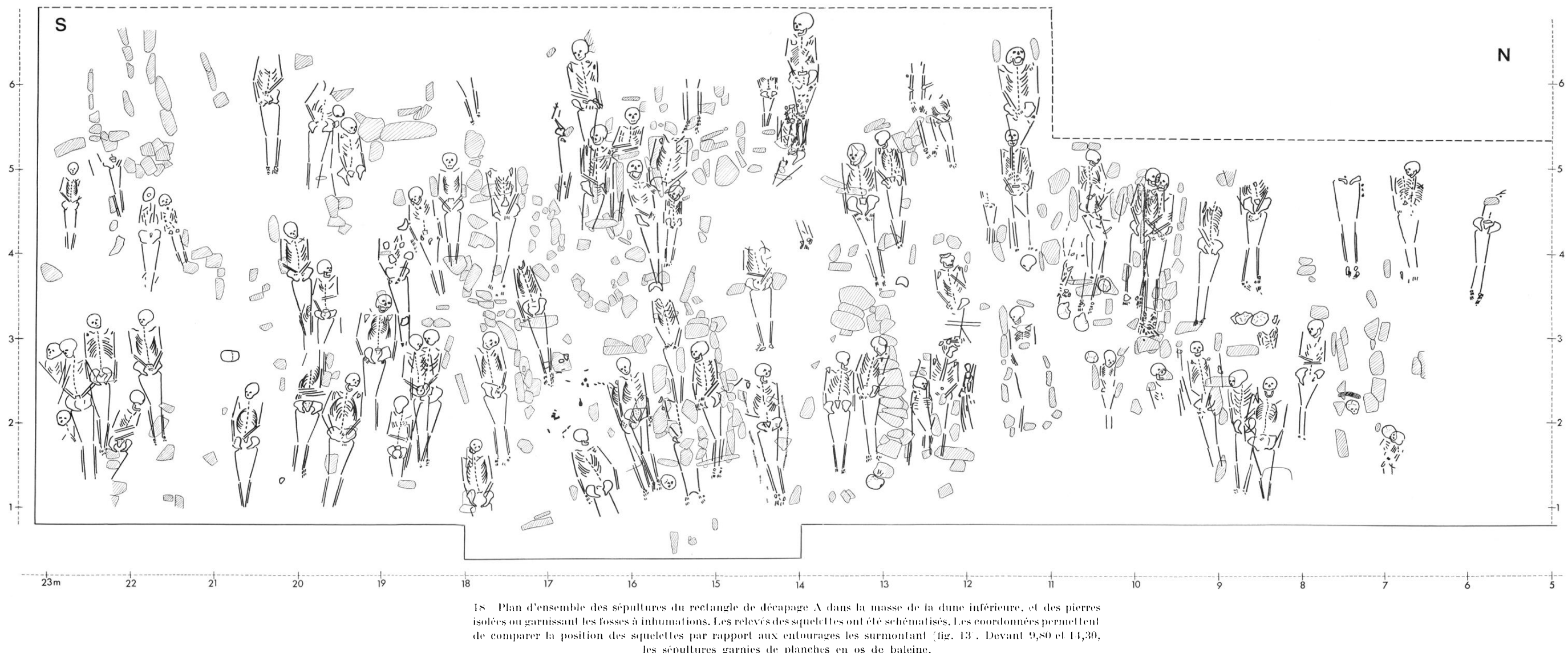




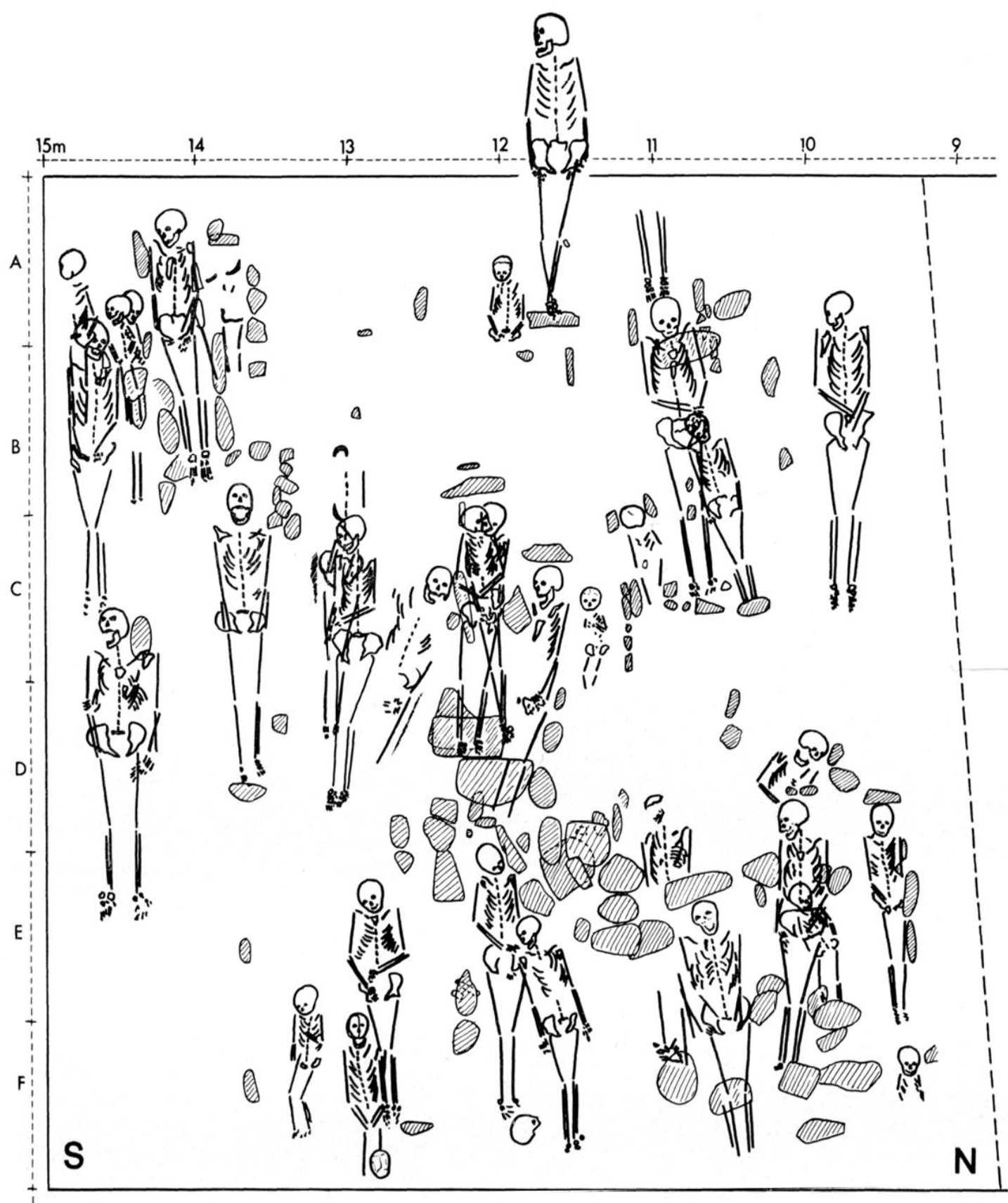

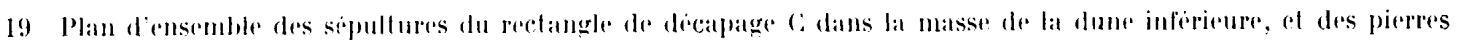

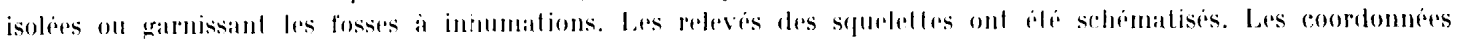

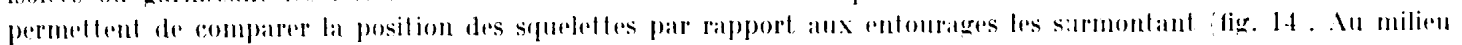

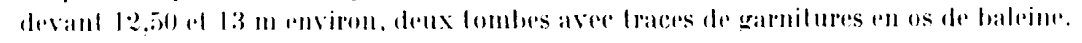




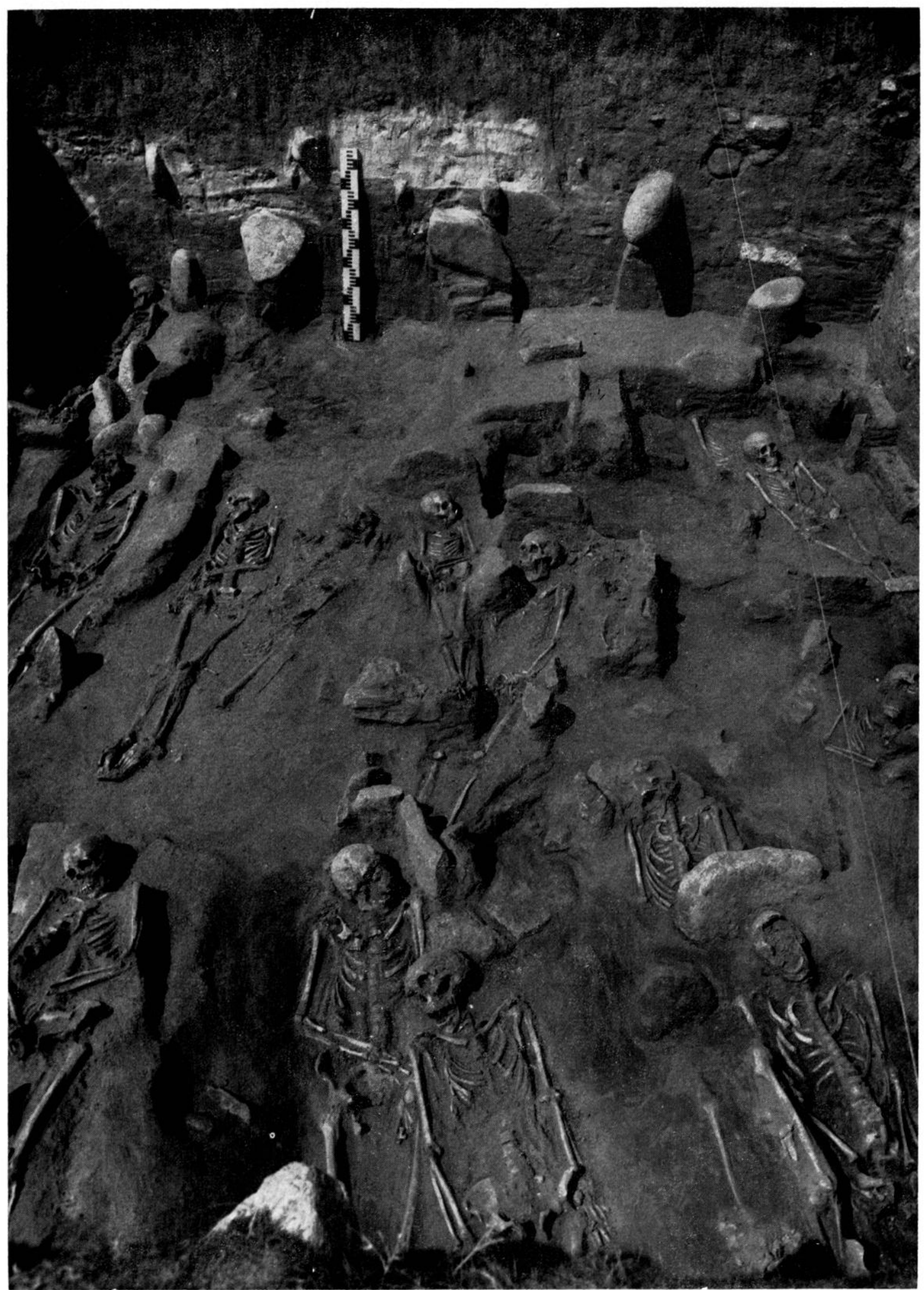

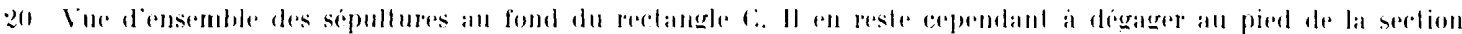
orcidentale. On motera les queldues varialions dorientations. 


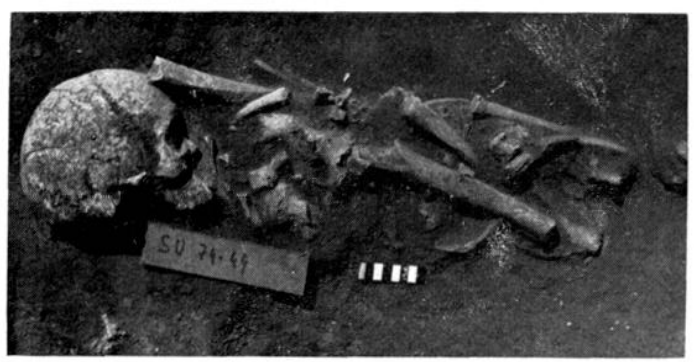

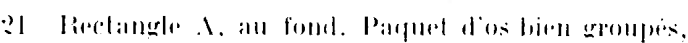
rrine (ompris.

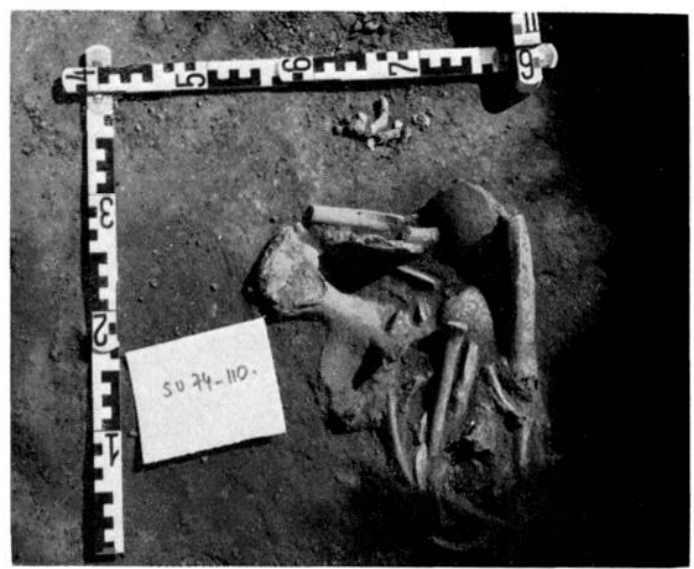

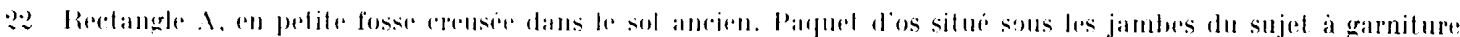

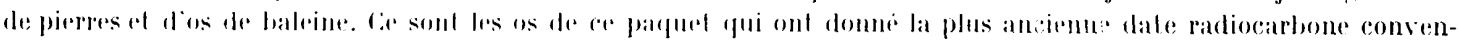
tiommelle de $3: 0$ ap. J. - .

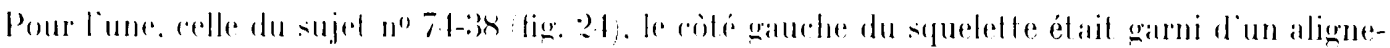
ment de pieres. landis que le cole droit était serre sur toule la longueur par une sorte de planche. en réalite peul-itre composile. alusi rectiligne que possible. éatise de 3 a $4 \mathrm{~cm}$, mais beaucoup plus mince ef irreguliere vers le haut du corps. Comme cette planche elait hallee dans une partie spongieuse de l'os. sit conservalion sel en fait lris variable, el resont plutot les traces qui nous en sont parvenues qu'un objel ronsistant. Meme imprégnés de matieres plastiques de consolidation, les fragments ont tris peu de tenue.

line autre sepullure, également masculine. celle du sujel no 7l-bit, dait bordé par deux de ces planches. A gauche se trouvait une planche curviligne ne bordant que la partie médiane du corps, a droite une rectilione sur loute la longrueur, mais probablement en deux pieces. Celte sépulture a été protécée el plat rée en vue d'un éventuel enlevement ultérieur.

Au cours de nos fouilles antrieures, nous avions également rencontre un fragment de cote de baleine, dont la signifioation est plus daire maintenant.

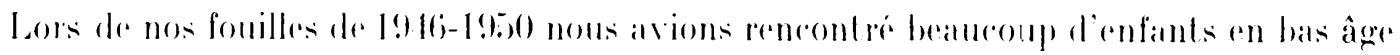

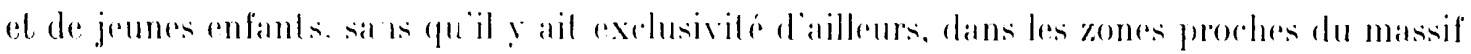
de blocage of de ruines el notamment enormement de hebes a son volsinage immédiat all

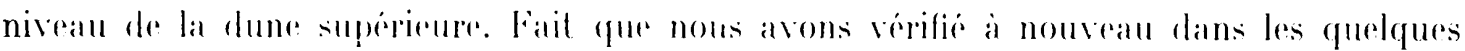

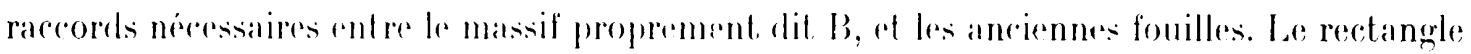
A etant nellement plus élogune. nous ny arons pas remeontre beancoup de tres jeunes enfants, non phus dailleurs que dans le reelangle li, mème a tourher le bord méridional

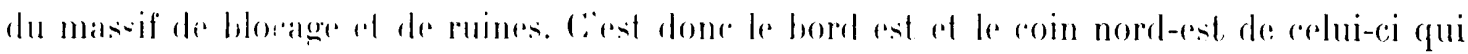

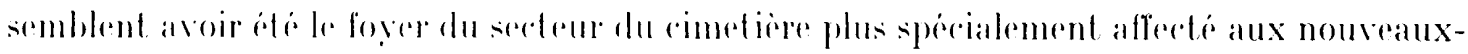
nes et lire jeumes enfants.

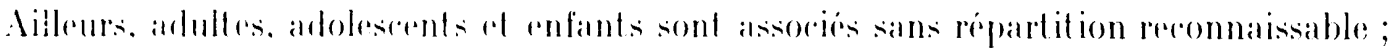

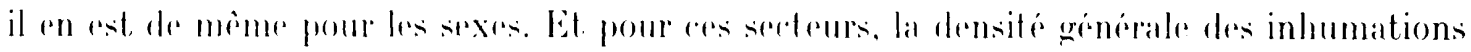

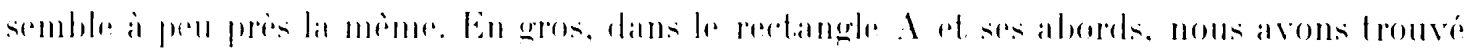

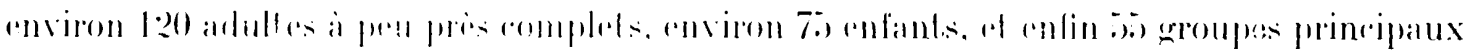

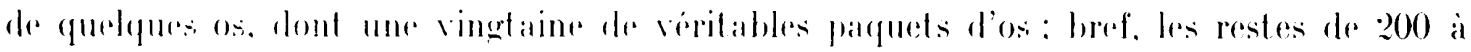

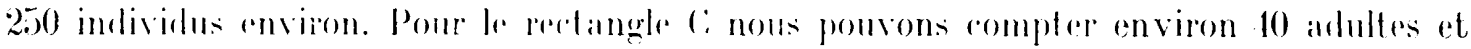



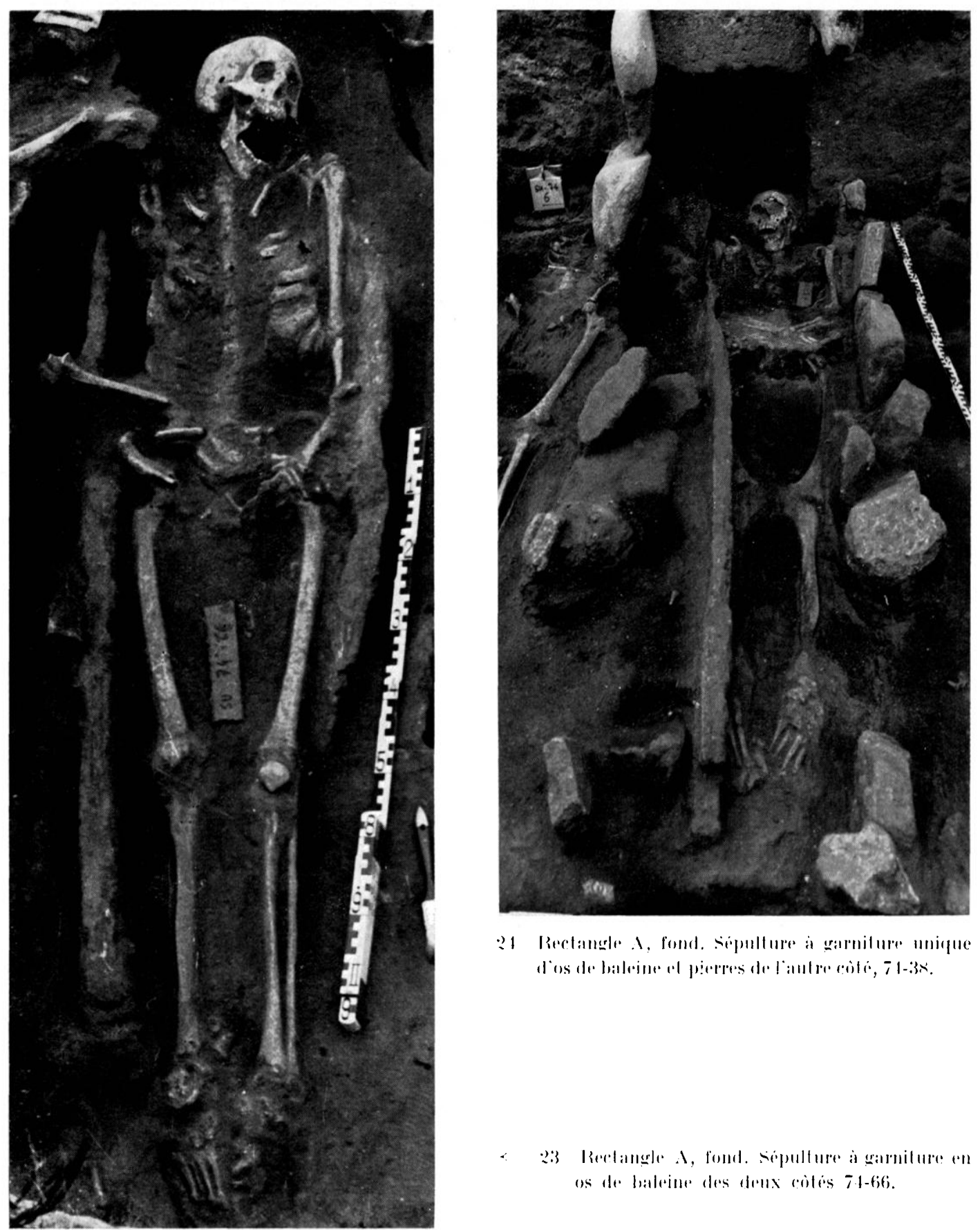

$\because 1$ Rerctangle 1. fond. Sipulture as garmilure unique

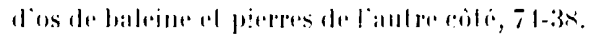

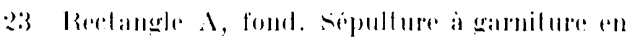

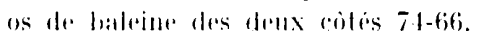

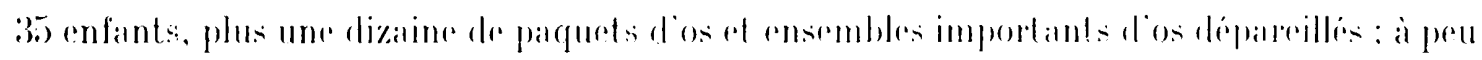
près les resters de 80 à 100 individus sans doute.

Comme partout. l'atat de conservation d'un individu est variable selon les malheurs

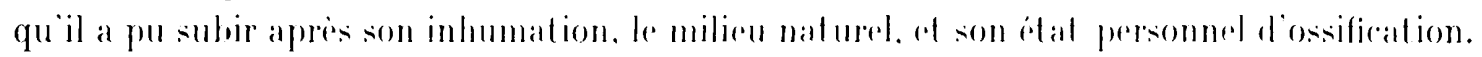

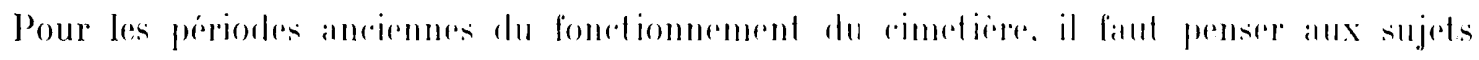

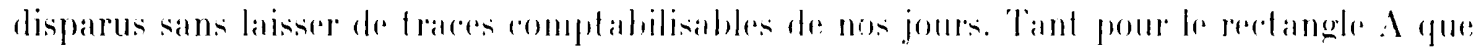

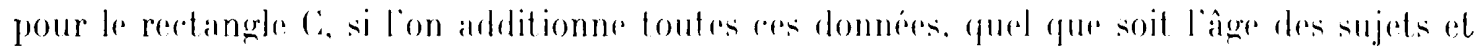


quelle que soit l'époque d'utilisation du cimetière. on obtient une densite moyenne d'orcupation de quatre individus au metre carré. Lés sondages un peu éloignés laissent supposer que "ette densité perut diminuer plus loin du centre principal du territoire funéraire. Son organisation pent varier.

I'ne tombe d'enfant du rectangle $\mathrm{A}, \mathrm{n}^{0}$ 74-7, atait garnie, derriere la tète, d'un objet rn os perfore à chaque boul, qu'on pourrait comparer a une pièce d'extrémite de berceau ou de hamare Cet objet doit ètre equalement en os de baleine; il n'y en avait malheureusement quiun. le bas du roops ayant été coupé par une autre sépulture. lanns la mesure où l'on peut l'interpreter comme tol, c'est l'unique objet mobilier décourert en association rertaine avec une sépulture.

Cis populations venues senterrer a saint-saturnin devatent etre tres pauress si l'on en juge par l'absence confirmée de tout autre mobilier funeraire. de monnaies. d'accessoires ou d'ornements du costume. agrafes, fibules, boucles, rivets, épingles, boutons, qui en bronze. en laiton ou en os auraient dù se conserver dans un tel milieu. Peut-être se faisaientils en bois dur ou en corne, mais un tel dépouillement généralisé pour un aussi grand nombre d’individus ne peut quétonner. On n’a bien entendu trouve aucune trace de clous de cercueils ou d'epingles de suaires. Les linceuls, s'il y en avait, devaient sans doute ètre rousus.

Les restes d'objets antérieurs dispersés dans la masse de la dune inférieure n'ont à ce point le vue aucune signification. Leur presence est purement fortuite. Il faut insister, comme exemple, sur un fragment de bracelet en bronze à contour perlé, objet caractéristique du Hallstattien (IIa B et (a). Il fut trouvé à toucher une côte humaine qui avait été colorée par ses produits d'altération. On romprend que les anciens fouilleurs aient de bonne foi associé squelettes at silex ou débris de bronze ou de fer et sépultures. Devant des petits paquets de rouille on parlait un peu vite de fibules, par exemple. Nous n'avons trouvé aucun objet de fer suffisamment bien conservé pour être identifiable, sauf peut-être pres d'une sépulture de la dune supérieure deux pièces an 1 qui nous semblent pouvoir être des marchoires dlun piège, descendu a ce niveau dans un terrier de lapin.

Aurune trace d"inseriptions ou de graffiti sur les pierese des entourages : araignant que les fouilles antérieures eussent pu les laisser échapper. on a recherché aver soin, ne serait-ce qu'une croix ou un rhrisme malhabiles, sans rien distinguer, mème sur les faress les plus planes des pierres teitieres.

Lne pierre déplacée et manifestement introduite tardivement est cependant d'un tres grand intérêt (fig. 2i)). Il s'agit d'un bloc de granite cylindro-conique, régulièrement façonné par bouchardage, fragment long de $1,25 \mathrm{~m}$, de diametres à la base de 0,40 et $0.35 \mathrm{~m}$, au sommet de $0.28 \mathrm{~m}$ dans les deux axes. Sa hase est effilée. l'autre extrémite est fracturée. Gn peut y reconnaître un morecau de fùt de croix, tel qu'on en connaît plusieurs dans la région. Ces fùts sont manifestement taillés dans des stèles de l'Âge du Fer par martelage des rainures. Sans aller bien loin. on en voit de tres grands a krö̈z-Veur. un peru à l'est de

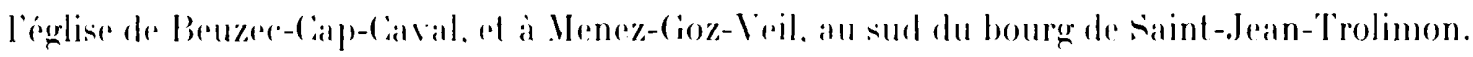

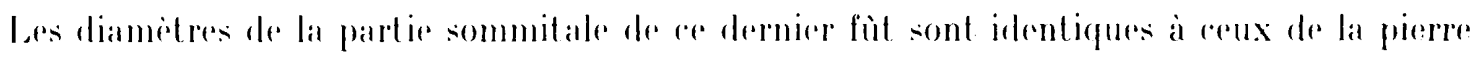
que nous avons découverte. (ce bloc se trouvait au fond d'une fosise peu profonde dane le 

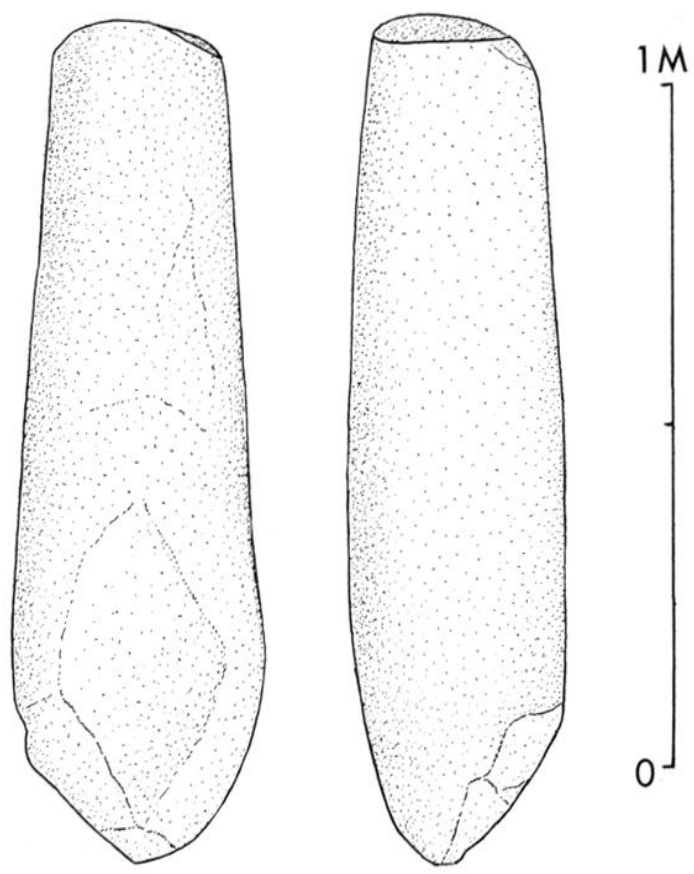

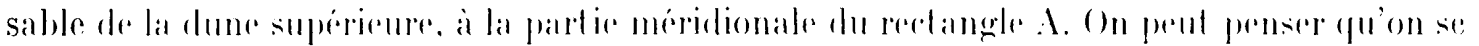

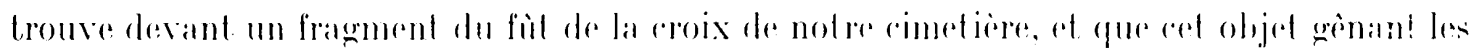

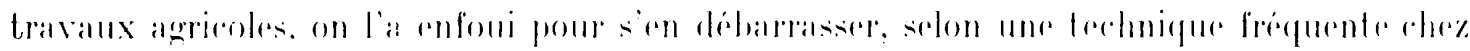
les cultivaleurs d'alutrofois.

\section{Les squelelles de rimelierer.}

On peut indiquer quelques domneses paleopalhologiques, le produit des fouilles antérieures ayant ede tres fructueux a cet regadt. La dentilion montre un laux de caries fres normal pour la

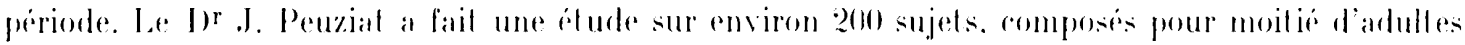

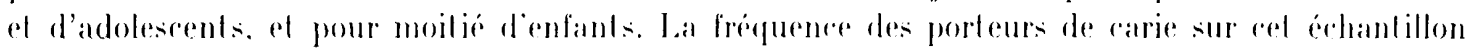

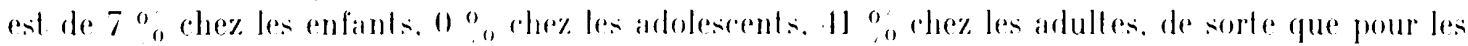

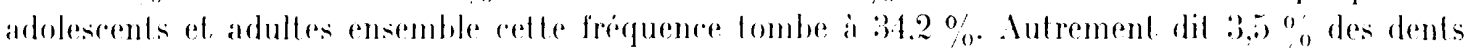

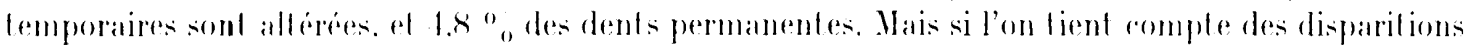

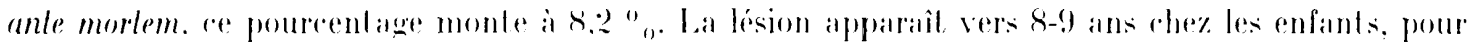
les dents temporaires. Pour les lents permanenles la rarie apparail comme une maladie de ladulte.

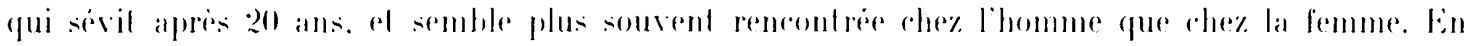

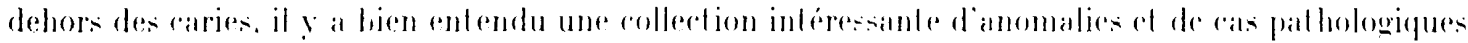
dentaires.

La colome vertebrale presente des ass de varialions usuelles. et hien entendu les bamales arlhroses on les icrasements des lombatres. mais rien de lres different de re que lon redrouse en clientible arluelle. notamment en milieu rural. Plusieurs ats de spina bifida. une soudure de deux dorsales. une soudure de l'axis al de la troisiome cervicale sont a noler. Il y a au moins trois ou

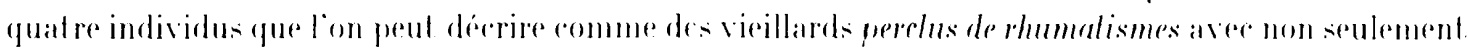


des colonnes verteblarles en l riste bal. mais pour l'un d'enormes exostoses au fémur. alu libia pour un aulre. un autre encore aver tibia el pérone soudes par le bas. Ches un aul re on voit une porese du colyle iliaque el des bavures arllorosiques a la tete fémorale.

Au point de vae trammalologique on peul signaler un fémur qui semble avoir subi une fracture intertrochanterienne de jeunesoe: une Prachure bien consolidée d'un tibia watuche vers le milieu de

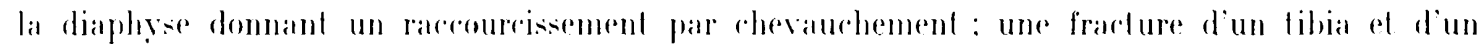
prene gatuches vers le bas de la diaphyse. en bois vert. In femur droil montre une belle exostose externe a la diaphyse : a genre de séquelle d'un arrachement musculaire est généralement interne al res ras sonl forl rares.

le produit des fouilles anlerieures avail donne quelques ras d'apophyses susfpil rochléennes a l'humerus. Xous an asors un aulre. ce qui peut al re le signe d'une endogamie assez probable, dans une telle population.

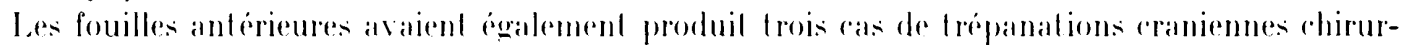
girales ${ }^{8}$. loutes frois aver survie. dont lune tries remarquable : eeci sans rompter un fragment de cràne montrant un hiseau caracléristique. Sos nouvelles fouilles nous ont procuré toute une série de cranes trépanes re qui porte le lotal a la quinzaine. C'est une des plus grosses roncentrations

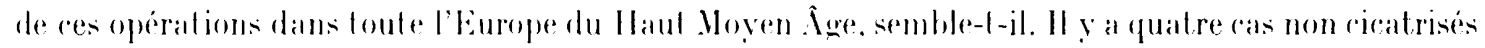
$0 u$ a peine. dont un au frontal droit. un au parietal gauche, un autre an pariétal gaurhe debordant sur le frontal. entin un au verlex el au pariegal droil dehordant sur le gauche. Ies six cas bien ridatrisés comprennent un cas an fronlal droit. deus au pariéal droit. deux aulres au pariétal droil aver dobordement sur le irontal pour l'un. sur l'oceipilal pour l'aulre, enfin un ras au parietal gatuche. Ces operalions sont de dimensions moyennes. d'un diametre variant entre 3 el fi cm. Il y a aussi un cas de lrépanalion incompliate on "symbolique" au milien du frontal, ainsi qu'une tres rurieuse operalion qui a ate rertainement pratique post mortem. une sorte d'autopsie. plusieurs Irails de coupe ayant débite l'arriere-gauche d'un eraine.

Mais si l'on mel de roble ces anomalies el ces curiosiles. comme les inévilables maryues des pelites el grandes misires de l'existence de quelques-uns. on est obligs de constater que dans l'ensemble on a aflaire a une population osteologiquement tres saine et robuste.

I) fail quon remarque des spécialisalions lopographiques par àges dans le cimeliere. qu'une partie et les plus fraciles des anciennes sépultures onl éte degradées ou se sont dissoutes, il ne serait pas statistiquemenl valable de tenter la moindre reconstilution démographique sur retle population sans avoir fouille la lolalite du cimeliere. Ce qui est evidemment impossible ni désirable ; d'ailleurs une bonne partie en a de détruite par la carriere au siede dernier. I)u moins sans cherrher trop de raflinements inutiles dans les délerminalions d'àge. peut-on se faire une impression, aelle d'une population paysamme normale d'il y a quelques sibeles, aver une forte mortalite infantile bien entendu. puis des déces a lous les àges. ar qui nemperchait pas un certain nombre de robustes vieillards d'alleindre un age cerlainement fort avancé.

Quelle est donc aette population au point de vue anthropohiologique? I e bilan des études sur les sujels fournis par les fouilles anterieures est rorroboré par un examen rapide des nouveaux documents, fe fout fournissant un ensemble precieux pour des fludes approfondies. Il sagril d'une population qui frappe par son homogenéite relative, ou se manifestent les traces d'une rertaine ronsanguinité. De sorte que les individus a raracteristiques extrimes par rapport a la moyeme ou hors serie sont rares. Ces faits contrastent aver les petiles series protohistoriques armoricaines dont nous disposons, de meme quaver certaines petiles series medievales, fres helerogines rharune ph elle-mime comme entre elles.

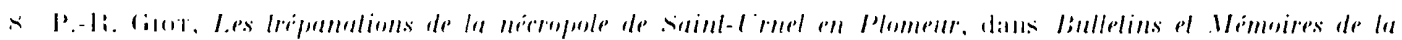

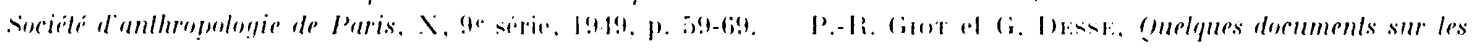

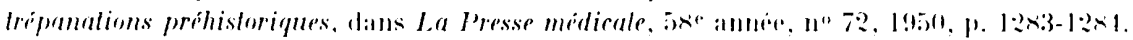


Bornons-nous a commenter les histogrammes de quelques mesures el déterminations fondamentales. Pour la stalure, on peut dire quelle entre par sa moyenne. dams la ralégorie anthropologique dite sur-moyenne. Pour l'époque cela veut dire que la taille était presque forte, et c'est le reflet du caractere sain et robuste d'une population qui profitait certainement de l'équilibre alimentaire du bord de mer. Il se pose un probleme de détermination des sexes, puisqu'il y a loujours indécision pour un certain nombre d'individus. et que les lables ou équations de détermination de la laille a partir des os longs ne sont pas les mêmes selon les sexes. C'est ainsi que pour l'échantillon de femmes (lelles que nous les avions délerminées par un premier examen d'ensemble) la médiane se trouve par rapport a l'échantillon d'hommes. a un point ou deux trop bas. et que la distribution des tailles des femmes est déficitaire du còté des grands sujets : c'est clair. une partie de celles-ci ont éé prises pour des hommes. Autrement dit quelques-uns des individus parmi nos pelits hommes doivent ètre reversés au sexe féminin. Ces considérations permeltent d'ajuster les moyennes provisoires el de dire que la taille moyenne de notre population doit itre de l'ordre de l68 am pour les. hommes. avec une distribution allant jusqu'à $18: 3 \mathrm{~cm}$ pour les tris grandes tailles. Il y a donc pas mal d'individus de forte stature, mais pas aussi gigantesques qu'on l'a parfois dit autrefois. Pour les femmes la taille moyenne doit ètre de l'ordre de $156 \mathrm{~cm}$. ce qui est également une belle stature. pour une population rurale de cette époque. Ces données sont basées sur les os du membre infériér d'environ (6) hommes pour io femmes adultes.

Pour l'indice cranien horizontal, nous avons pu intégrer les sujets des fouilles antérieures, d, pour prés de 160 sujels. sexes confondus, la médiane est a 77 . En considérant l'histogramme. on peul. dire que nous avons aftaire à une population dolicho-mesorrane, aver une minorilé brachycrane. La forme de la distribution comme l'ensemble des données morphologiques montrent que pour l'essentiel, à part de rares individus discordants, ces brachycranes ne sont que le versant de la distribution. qui s'étale des indices 68 a 90. Les indices moyens de hauteur du ràne montrent qu'il s'agit essentiellement de rânes bas ou moyennement élevés. mais aver davantage d'irrécularilés. mais pratiquement pas de crânes hauts. Les indices faciaux sont moyens avec une forte proportion de laces larces et hasses. Parmi les caractères descriptifs, notons une majorité de cranes de forme ovoüde en norme verticale, et une nette tendance à une saiblie occipitale. Én général la diflérencialion sexuelle est bien marquée.

Etant donné que dans l'ensemble du Massif Armoricain, les conditions nalurelles sont lris: défavorables à la conservation des ossements anciens, le cimelière de saint-l rnel offre une information presque unique, inespérée el abondante sur les populations de la Bretagne occidentale au Haut Moyen Àge. In examen préliminaire ne permet pas d'y déceler des variations significatives diachroniques.

Mème si de tres rares individus brachyeranes s'y rencontrent. les sujets de siant-Crnel ne ressemblent en rien par l'ensemble de leurs caracteres aux Bigoudens, cest-i-dire aux habitants actuels de la region ${ }^{9}$ : on peut dire que les gens de saint-l rnel ne sont encore en rien "bigoudénisés" Le phénoméne de la "bigoudénisation " est donc neltement postérieur a l'an mil el reste à élucider. Il semble même postérieur au Moyen Âge proprement dit, quoiqu'il soit une variante de la "brachycéphalisation" universelle des populations européennes au Hoven İge. Qu'il se soit produil par Iransformation ou par remplacement partiel de la population. il résulte tris certainement pour une

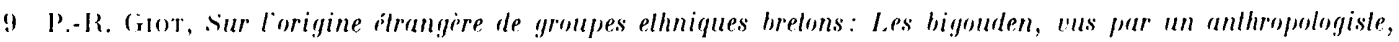
dans . Vouvelle renue de Bretagne, 1. 3, 19.49, p. 66-69; -. P.- R. (ilot, Armoricains el Brelons, élude anthropologique,

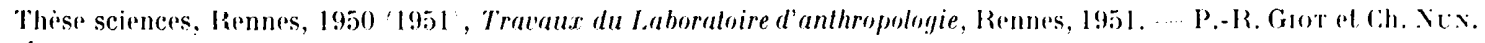
Élude anthropologique de lenclate de Kerily-Penmarch, Finistire, dins Comples rendus du afje congres des Socialés

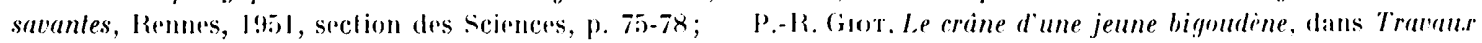

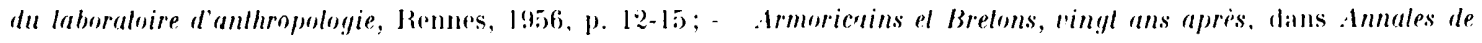
Brelagne, I.XXIX, 1972, p. I03-11x; Armoricains el Brelons, perspectives nowelles sur les Bretons, ilid.,

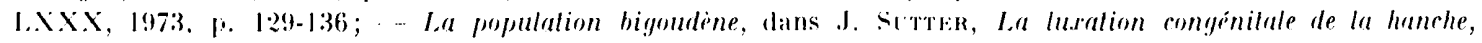
dans Tran'aur el locuments, Instilal national d'études démographiques, n" 6.2, 1972, 1). 1.4-333. 
large part des eflets de lendogamie pour aboutir a une frequence aussi grande diune variete lypologique aussi netlement singularisee par mapport aux populalions voisines.

si lon veut faire une comparaison rariologique. disons que les habitanls de siant-saturnin correspondent asse\% bien a la notion des "Europeens du Cord-()uest ". rassemblant les descendants des storks primitifs des peuplements of des réments subnordiques issus soit d'apporls nouveaux. soil de la transformation des premiers. On peul envisager plusieurs hypotheses de travail : ce seraient. des descendants des populations autorhtones gauloises armoricaines: mais a vrai dire sil y a des ressemblances aver quelques irdividus motamment aver deux rames de siles lout voisins. Tronoan el Kerviltré). on se rend comple quil y a des diberenesentre les sujets de notre rimetiore. et les quelques séries d'Armoricairs de l'ỉge du Fer qui sont incontestables rhronologiquement parlant. beaucoup plus voisines de lypes médilerraneens graciles: re seraient des descendants domplan-

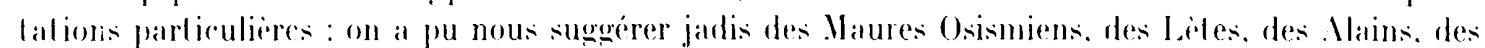
sixons voire mème des Vikings. hypolheses qui ne résistent guere à l'examen ; enfin. re seraient lout simplement des immigrants Bretons et leurs descendants. avec évenluellement un léger métissage aver les rares Armorianins survivant dans res régions en principe assey désertés et dépeuplés.

Incontestablement rette derniere interprétation est ha seule sérieuse. lisons tout de suite que les caractipes anthropobiologiques parfois considérés comme archäques ahez les gens de saintsaturnin se retrouvenl assez farilement. semble-t-il. dans loutes les séries du sud-ouest et de l'()uest. des lles Britanniques ef qui sont malheureusement peu nombreuses a avoir eté publires). Ies similiturles des Brelons desaint-sal urnin aver leurs cousins bril anniques insulaires sont indéniables. Solre cimeliere nous donne donc une bonne image anthropobiologique des immigrants Brelons.

si les hommes de saint-salumin se haissent mal comparer aver les habitants actuels du Cap-Caval lou pays Bigouden). par contre ils sont beauroup plus romparables a ceux du Cap-sizun cou de la région de la Poinle du Raz) qui, de loule la Brelagne, ont le plus faible indice céphalique et une bonne taille moyenne. Il y a quand meme mille ans de différence et bien des vicissitudes entre les hommes de sainl-sialurnin el les Capistes, presque fout comme entre eux et les Bigourlens.

\section{Lisneirontremenl hislorique ol archeologique.}

II se pose beaucoup de questions d'ordre général. Quelle etait rette population qui est representere aree une telle abondance dans le rimetiere de saint-salurnin? Compte tenu des donnés oblenues sur l'extension minimale du rimotière al sur la densité des inhuma-

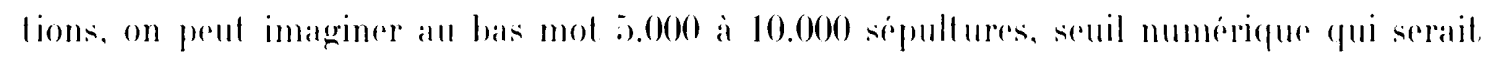

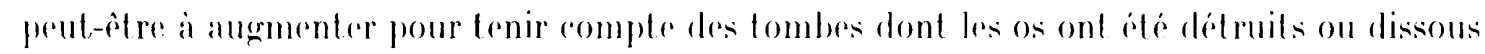
à la suite des rémplois du mème emplacement.

Le retour au site, apres le depott romplet de la dune superieure qui montre des sepullures assez hâtives ou negligés. pourrait faire penser à une épidémie ou à une famine. capendant on a trop tendaner à faire appel à ces explications un peu faciles ; en tout cas relte phatse peut grouper environ un quart du nombre des inhumalions reonstatés sur les slurfares exploress.

Bien entendu on ne peut tabler que sur les sepultures d'adultes ed de grands enfants. La mortalite infantile entendur romme jusqua a 1 an environ, alteignait encore parfois

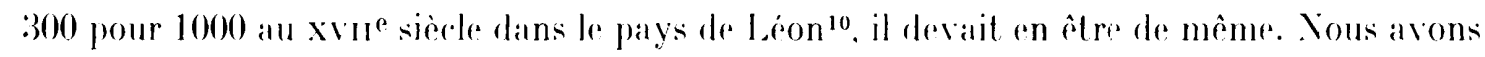
vu quan endroit preférentiel était réservé dans le cimetiere au moins aux periodes les plus

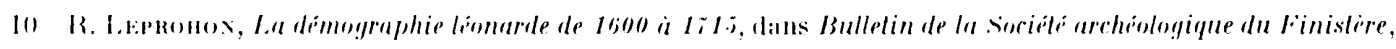
XI:IX, 1972. 1. 7115-730. 


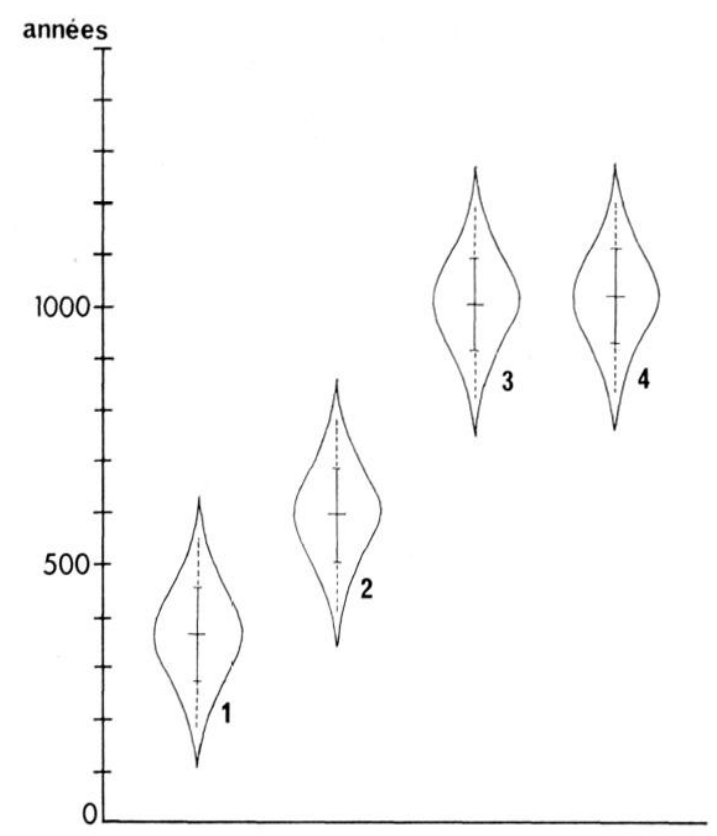

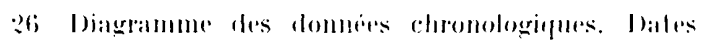
radionabone ralibries selon F. K. Ralph, lisurés ell romphes de probabilitio entomant des aires regales. I

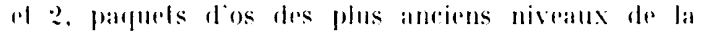
dume inferienere: 3 e. 1 , as des tombes des niveran de la rlune suppirienre.

récentes de son utilisation, pour les nouveaux-nés; il semblait avoir ete choisi ad sancles. ()n ne peut rien on extrapoler pour les débuts du cimetière, où la situation était peut-être plus diffuse.

Revenant a la population dans son ensemble, at rompte tenu d'un taux de mortalite moyen pour une population rurale encore assez primitive au moins 2.5 a 30 pour 1000 j, be rimetiere pourrait être celui l'une population de soo personnes, a qui pent correspondere a une forte paroisse de l’epoque. ()n peut se representer le peuplement comme peut etre dix fois moins dense que celui de nos campagnes traditionnelles. les habitants étant groupess par villages de quelques familles, les rares petites aggolomérations ressemblant à peine aux phes petits de nos chefs-lieux de paroisses.

\section{La chronologyir.}

Xous devons nous appuyer sur des dabations radiométriques. par le dosage du radiocarbone. Le temps exprimé par le radiocarbone ne s'est pas exactement deroulé a la même vitesse que le temps absolu. Pour comparer les résultats obtenus aux données historiques, il est indispensable de proceder a la "ralibration" de ces dates a l'aide des meilleurs tables disponibles. tout an exprimant ces corrections arec toutes les précautions utiles. Il est également nécessaire de les figurer sous une expression probabiliste (fig. :26)"1, de manière à bien faire salisir le caractère aléatoire de cess determinations d'âge.

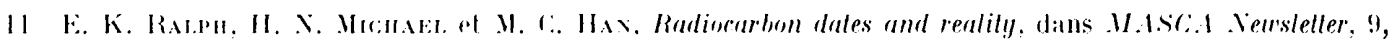

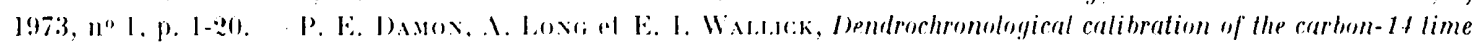

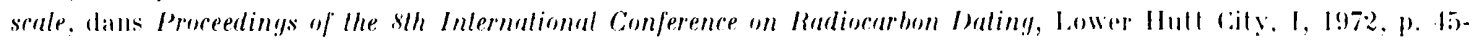

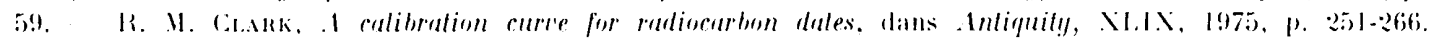

B. B. WAR p. :29-47: erralum 111, 1976, 1. w. 
Pour tenter de saisir an plus pres la date du rommeneement de l'utilisation du cime-

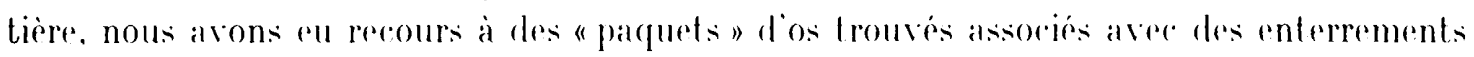
eux-mèmes estimés plus anciens. On a daté ainsi leurs prédécesseurs.

L'un des deux résultats obtenus. dont la valeur la plus probable se situe vers joja à 600 ap. J.- $\therefore$. ne pose aucun problème. Le cimetière était certainement en usage à cette date, mettement postérieure alu grand flot de l'émigration bretonne.

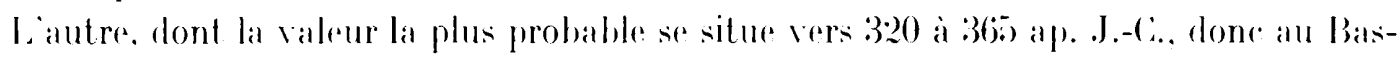
Empire, doit donner lien a discussion. Bien entendu. statistiquement parlant, il reste

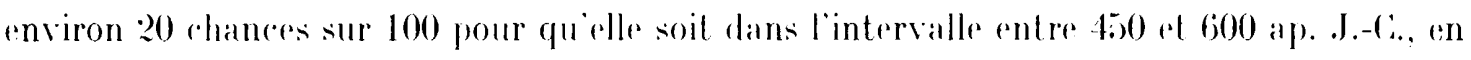
valeurs arrondies, auguel cas elle ne devrait pas nous troubler davantage. Sinon, indique-telle que le cimetière etait dejà fréquenté avant l'effondrement définitif de la sourerainete romaine en Armorique?

L'établissement gallo-romain le plus voisin, est celui de Tronoan ${ }^{12}$ qui aurait fourni plus de 200 monnaies romaines, dont les dernières seraient de Constantin le Jeune. loans la plupart des établissements de la région. la circulation monétaire s'arrête à Constantin et ses successeurs immédiats, bref vers 3:00. La question n'est done pas vaine.

Mais il faut noter que la tendance générale des spécialistes de l'histoire des Bretons est de penser que l'emigration de ceux-ci a commence beauroup plus tot, et que par conséfuent on peut avoir affaire aux sépultures diune colonie précoce de Bretons.

Il est donc difficile de conclure sur le moment de départ du cimetiere. On doit ètre raisonnablement assuré qu'il etait en service an re sierle.

\section{Pierre-Roland Giot et Jean-laturent Vonvier}

\section{APPINDICis}

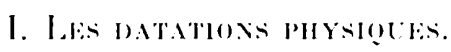

Les datations radiocarbone ont été effectuées au Centre des Fables Radioactivités du C.A.R.S. a (Gif-sur-Yvelle, sous lia direction de .lme (i. Delibrias, que nous sommes heureux de remercier ici. Les datations sur ossements ont bien entendu été opérées selon la méthode par extraction du collagrène.

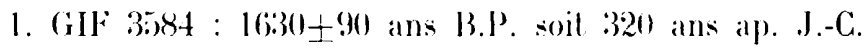

Paquel d'os sil-74-109 silué dans le vieux sol sous les pieds du sujet sil -74-3x ll'homme a

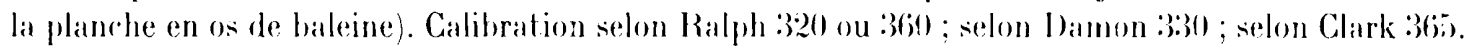

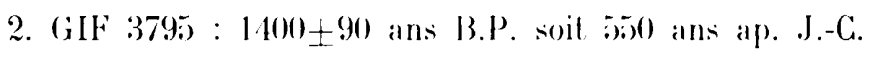

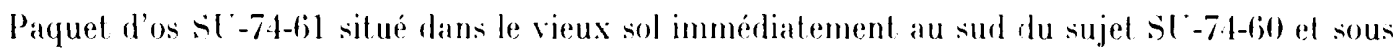

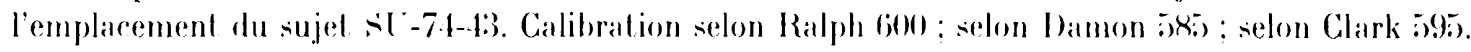

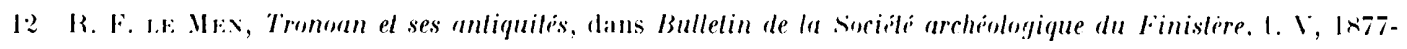

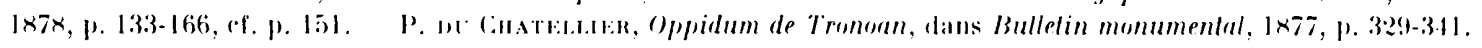




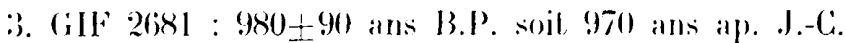

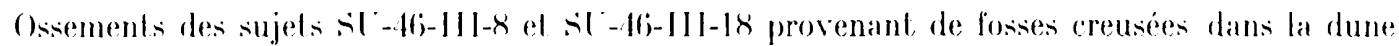
inferieure mais dalant de l'époque de la dune supérieure. Calibralion selon Ratph loon: selon Damon 990 ; selon Clark $100 \%$.

4. (ilf 2296 : $970 \pm 90$ ans B.P. soit 980 ans ap. J.-C.

Ossements de divers sujels st -on depareillés de la dune superieure. Calibration selon Ralph 1010 : selon Damon 1000); selon Clark 1010.

5. (iIF :375) : 1300 \pm 90 ans B.P. soil 650) ans ap. J.-C.

Charbons de bois du chantier B (6-7 C-J)) sous un pseurb-pavage en surface de la dune infericure.

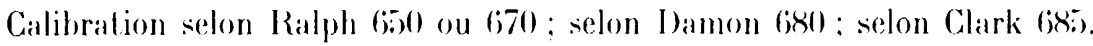

Ces charbons de bois définissent un niveau qui recouvre un trou de poteau reusé dans la dune inférieure. Il devail y avoir une construction en bois, dont on a tout lieu de penser que ce fut une sorle doratoire. Dans la masse de la dune inférieure, sous re trou de poleau. il y a des sépullures plus anciennes. qu’il chail intéressant de dater :

6. (ilf $4071: 1310+90$ ans B.P. soit b40 ans alp. J.-C.

Ossements du sujet sl-7-171 situe juste en dessous du trou de poteau. Calilialion selon

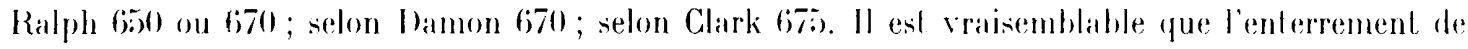
re sujel a précédé de trés peu l'édilication de la construction en bois. Ces deux dernieres dales procurent une tres bonne confirmation de la fréquentation du site el de la pleine utilisation du rimeliere vers le vile simele.

\section{I. VILIE: NATERLL.}

\section{Sérlimentologie.}

Analyses sédimentologiques (J.-L. .onnier) des échantillons pris en $197:$ dans la partie méridionale de la coupe occidentale du rectangle $A$.

Teneur en carbonate de calcium:

Dune supérieure $4(2)$ $54,0 \%$ de $\mathrm{CaCO}_{3}$

Sol intermédiaire.

Base de la dune supérieure $4(1) \ldots \ldots \ldots \ldots 43,0$

Dune inférieure $8 \ldots \ldots \ldots \ldots \ldots \ldots \ldots \ldots, 29,2$

Sol ancien $9 \ldots \ldots \ldots \ldots \ldots \ldots \ldots \ldots \ldots, 8$

Dosages faits au ralcimitre Bernard.

Minéraux lourds:

Dune sup. $4(2)$ Dune inf. 8 Sol ancien 9

\begin{tabular}{|c|c|c|c|}
\hline 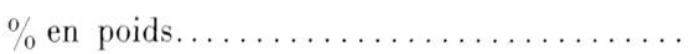 & 1,1 & 1,1 & 0,6 \\
\hline Grains opaques p. 100 grains.............. & 25,8 & 18,4 & 30,2 \\
\hline Grains altérés p. 100 grains............. & 18,1 & 26,4 & 22,2 \\
\hline \multicolumn{4}{|l|}{ \% p. 100 grains transparents : } \\
\hline Hornblende..... . & 18,5 & 23,0 & 31,0 \\
\hline$\ldots \ldots \ldots \ldots \ldots \ldots \ldots$ & 10,3 & 12,5 & 9,2 \\
\hline Grenat.......... & 43,8 & 23,6 & 31,0 \\
\hline Zircon.......... & 0,0 & 0,0 & 4,9 \\
\hline Tourmaline . . . . . . . . . . . . . . . . . . . . . . . & 8,9 & 9,7 & 5,6 \\
\hline
\end{tabular}


Staurotide.

2,7

15,1

0,7

0,0

0,0

0,0
5,5

22,2

0,0

2,8

0,7

0,0
7,7

9,2

0,0

0,0

0,7

\section{Morphoscopie:}

Grains \%

$\mathrm{NU}$

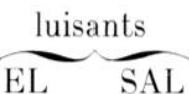

mats

Dune supérieure $4(2)$

13,6

Sol intermédiaire.

Base dune supérieure $4(1)$

Dune inférieure 8 .

Sol ancien 9 .

31,5

76,4

$\mathrm{NU}=$ non usés $; \mathrm{EL}=$ émoussés-luisants $; \mathrm{SAL}=$ subanguleux $; \mathrm{EP}=$ émoussés-picotés ; $\mathrm{EM}=$ émoussés-mats.

Granulométrie:

$\%$

$\mathrm{SG}$

Dune supérieure $4(2)$

Sol intermédiaire.

supérieure $4(1) \ldots \ldots \ldots \ldots \ldots \ldots \ldots \ldots$.

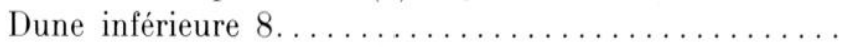

Sol ancien 9 .

Tamis normalisés AFNOR (fig. 27).

$9,9 \quad 57,6 \quad 4,5 \quad 14,4$

$5,0 \quad 56,7 \quad 5,0 \quad 6,7$

$16,3 \quad 36,6 \quad 7,3 \quad 13,0$

$6,4 \quad 45,2 \quad 4,0 \quad 12,9$

$4,2 \quad 11,0 \quad 2,5 \quad 5,9$

\section{Indices granulométriques:}

\begin{tabular}{|c|c|c|c|c|c|}
\hline & Q25 & Md & Q75 & $\mathrm{Hq}$ & Asq \\
\hline Dune supérieure $4(2) \ldots \ldots \ldots \ldots \ldots \ldots$ & 186 & 210 & 240 & 0,5 & $-0,05$ \\
\hline Sol intermédiaire................. & 178 & 214 & 258 & 0,8 & 0,0 \\
\hline Base dune supérieure $4(1) \ldots \ldots \ldots \ldots$ & 190 & 214 & 240 & 0,5 & 0,0 \\
\hline Dune inférieure $8 \ldots \ldots \ldots \ldots \ldots \ldots \ldots$ & 182 & 208 & 240 & 0,6 & 0,0 \\
\hline Sol ancien $9 \ldots \ldots \ldots \ldots \ldots \ldots \ldots \ldots$ & 190 & 372 & 1150 & 3,9 & $-1,0$ \\
\hline
\end{tabular}

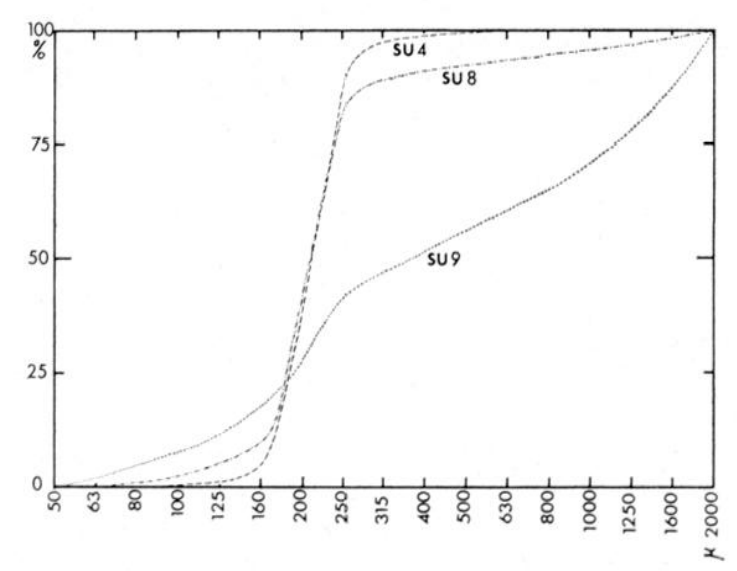

27 Courloes gramulometriques des échantillons des sables de Saint-Saturnin. 


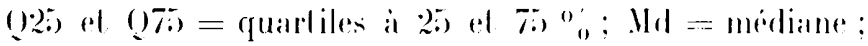

$\mathrm{H}_{\mathrm{y}}=$ indice d'hétérométrie interquarlite:

Isy = indice d'asimétrie interquartile.

Ces rísultats sont à comparer à ceux publiés pour d'autres sites de la région de lat Baie d'. Audierneris.

\section{Ecologlegie.}

En ce qui concerne la faune de Vollusques et de Mammifères rencontrée parmi les déchets de nourrilure. nous n'avons pas d'espeeces diltérentes a signaler parr rapport aux listes de notre article de 1951 (cef. note 4).

Au point de vue écologique, on se trouve selon les estimations des historiens comme des climaLologistes, pendant une décrue glaciaire. un peu plus accentuée que l'actuelle, aver un climat tiede et doux, mais qui en Europe occidentale a pu se doubler d'une pluviosité défaillante et de sècheresses par évaporation ${ }^{14}$. Les migrations des sables dunaires qui se sont mises en route à la fin de la période. d'utilisation du cimetiere et qui y ont mìme sans doute mis un terme, y sont peut-itre liées, plus qu'une régression marine. En effet une formation a petits galets et gravillons marins a occupé une assez vaste étendue au-dessus des dunes en bordure de la baie d'. Ludierne aux environs de la pointe de la Torche. lille a été dégradée, surtout dans les trente dernieres années, par l'exploilation humaine. Les coquilles brisées mèlées à ces gravillons marins ont donné une date radiocarbone de 110$)^{\prime}$ 士90 ans B.P., soit 8io0 A.D. (Gif 891). Les gravillons se trouvent a quelques mitres au-dessus des plus hatutes mers artuelles. La mise en place par de grandes tempetes en fonction du niveau actuel de la mer étant difficile a concevoir. on a pu penser voir la l'indire d'une transoression marine ayant dépassé de 1 i $2 \mathrm{~m}$ le niveau actuel au cours de l'ire chrétienne. Cependant en 1896 et en 1924 la région de Penmarc'h a connu des inondations marines momentanées assez curieuses, mais sans grands mouvements de sables, par effet "barometrique".

Quoi qu'il en soit, la remise en mouvement des dunes vers la fin du premier millénaire de notre ere a pu lrouver son approvisionnement dans la formation i galets et gravillons qui s'est superposée au cordon littoral normal el à ses dunes assoriées.

L'approvisionnement de la dune ancienne au cours du premier millénaire avant notre ire peut itre également date de maniere intéressante. En effet, à environ $1 \mathrm{~km}$ au nord de la presqu'île de la Torche, presque au niveau de siant-sialurnin, il allleure de temps à autre sur l'estran actuel, au niveau de mi-marée, émergeant du sable de la plagee. un gries coquillier qui a été daté par le radio(arbone de $2670 \pm 110$ ans B.P. soit 720 arant notre ire (Gif 1100$)$. Cethe sorte de lumachelle ou de gris de plage, d'au moins un mictre de puissance est une consolidation qui s'est faite en régime terrestre pendant la régression marine qui caractérise en Armorique l'Âge du Fer et le début de notre ire, pendant que le trop-plein des sables étail mohilisí par le vent. Bien entendu les dates radiocarbone. sur coquilles marines doivent ìtre prises en envisageant des écarts plus grands que sur d'autres maljeres carbonées.

Comme nous l'avons dit, en divers points de la Baie d'Audierne, il y avait une tradition selon laquelle les sites còtiers auraient été envahis par les sables "l'année qui porte quatre bàtons dans ses chiffres " 1111 . H. Le Carrquet l'a publiée pour l'établissement de saint-Onneau au Cannaëc a Trey-Goarem en Esquibien où, parmi les ruines de constructions médiévales, il a également trouvé

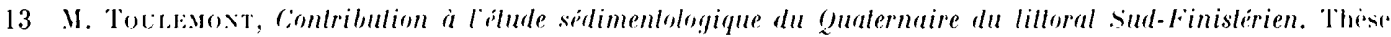

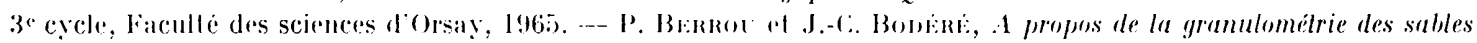

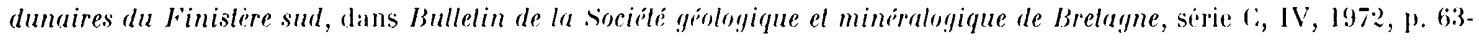

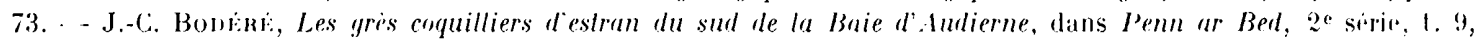
$\mathrm{n}^{\circ} 73,1973$, p. $\times 6-933$.

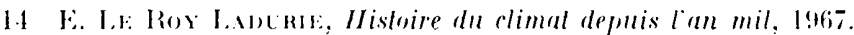


une monnaie de Conan I ${ }^{15}$. Ilme Le Bars el feu (i. Monot nous ont rapporté la mème tradition pour les palues de Tréguennec et de Plomeur. ou les dunes ont pu recouvrir bien des villagres. Ėn effet. a Tréguenner. dans le quartier de Kerguellec-Palud, les ruines abondent sous les sables. Celle qui fut fouillée en 1937 par (i.-A.-L. Boisselier nous avail servi de site type pour définir la "poterie onclueuse ". M. X. Vigouroux nous a signalé. à quelques centaines de metres de là. les fondations d'une autre maison sous la dune. avec "poterie onctueuse "fondations qui sont apparues suivre un tracé circulaire sur une courte longueur, rappelant les maisons a pignons en abside du Morbihan ${ }^{16}$.

P.-R. G. et J.-L. M.

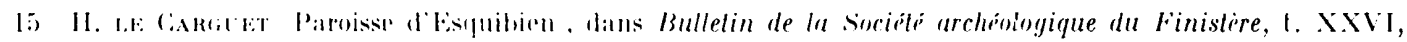
1899, p. $126+42 \times 2$.

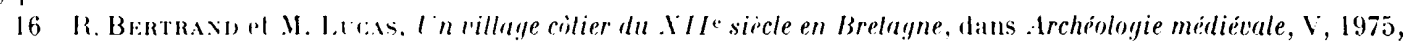

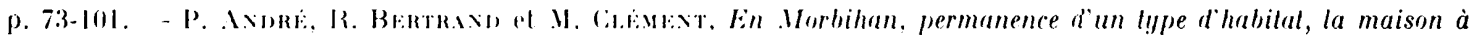
pignons en abside. dans . Irchenlogia. n" 97 . andit 1976, p. $2 \times-36$.

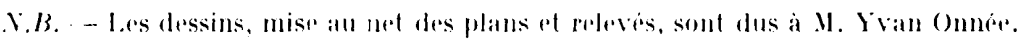

